\title{
Потенциал использования молекулярных маркеров в селекции сои
}

\author{
H.A. Виниченко (D凶, E.A. Салина (D), A.B. Кочетов (ID)
}

\begin{abstract}
Аннотация: В мировой экономике соя является ведущей зернобобовой культурой. Уникальный биохимический состав, технологичность производства, универсальность применения обеспечивают этой культуре значительный вес в национальных продовольственных программах разных стран. В настоящее время ведется активная селекционная работа по выведению новых улучшенных сортов сои. В связи с этим большое значение приобретает получение молекулярно-генетических маркеров, позволяющих осуществлять паспортизацию сортов, а также маркировать отдельные гены качественных признаков и группы генов, контролирующие количественные признаки. В обзоре обобщена актуальная информация о молекулярных маркерах, связанных с такими важными признаками сои, как размер семян, содержание белка, масла, регуляция сроков цветения и созревания, устойчивость к различным заболеваниям и абиотическим стрессам, фиксация азота.
\end{abstract}

Ключевые слова: соя; молекулярные маркеры; локусы количественных признаков; маркер-ориентированная селекция; геномная селекция.

Благодарности: Работа поддержана бюджетным проектом № 0324-2019-0039-С-01.

Для цитирования: Виниченко Н.А., Салина Е.А., Кочетов А.В. Потенциал использования молекулярных маркеров в селекции сои. Письма в Вавиловский журнал генетики и селекции. 2020;6(3):107-125. DOI 10.18699/Letters2020-6-15.

\section{The scope of use of molecular markers in soybean breeding}

\author{
N.A. Vinichenko (iD) $₫$, E.A. Salina (iD, A.V. Kochetov (iD)
}

Abstract: In the global economy, soybean is one of the leading legumes. The unique biochemical composition, high level of agrotechnology and production, wide range of products applications make this culture highly attractable for agricultural industry of many countries. Currently, effective breeding is underway to develop new improved soybean varieties. In this regard, it is of great importance to identify of molecular genetic markers for genotyping of varieties, as well as to mark gene alleles of qualitative and quantitative agricultural traits. In the review, we summarize current information on molecular markers associated with important soybean traits such as grain size, protein and oil content, flowering and maturation regulation, resistance to various diseases and abiotic stress, nitrogen fixation..

Key words: csoybeans; molecular markers; quantitative trait loci; marker-assisted selection; genomic selection.

For citation: Vinichenko N.A., Salina E.A., Kochetov A.V. The scope of use of molecular markers in soybean breeding. Pisma $v$ Vavilovskii Zhurnal Genetiki i Selektsii = Letters to Vavilov Journal of Genetics and Breeding. 2020;6(3):107-125. DOI 10.18699/Letters2020-6-15 (in Russian)

\section{Введение}

Соя (Glycine max (L.) Merrill) (рис. 1) - важнейшая зернобобовая культура в мире, обладающая комплексом ценных свойств (Абугалиева, 2013). Разнообразие химического состава сои позволяет использовать ее как продовольственную, кормовую и техническую культуру, а способность к симбиозу с клубеньковыми бактериями Bradyrhizobium japonicum, позволяющая фиксировать большое количество атмосферного азота, объясняет широкое использование сои в качестве сидерата. Сою выращивают более чем в 60 странах расположенных в условиях умеренного, субтропического и тропического климата. Основные производители сои США, Бразилия, Аргентина, Китай. Интересно, что средняя урожайность сои в различных странах существенно различается: так, в 2013 г. Бразилии она составила 28.4 ц/га, в Аргентине - 28 ц/га, в США - 27.9 ц/га, в Парагвае - 25.8 ц/га, в Китае - 17.7 ц/га, а в Индии всего лишь 9.5 ц/га. Однако показатели урожайности сои ежегодно повышаются. Так, в 


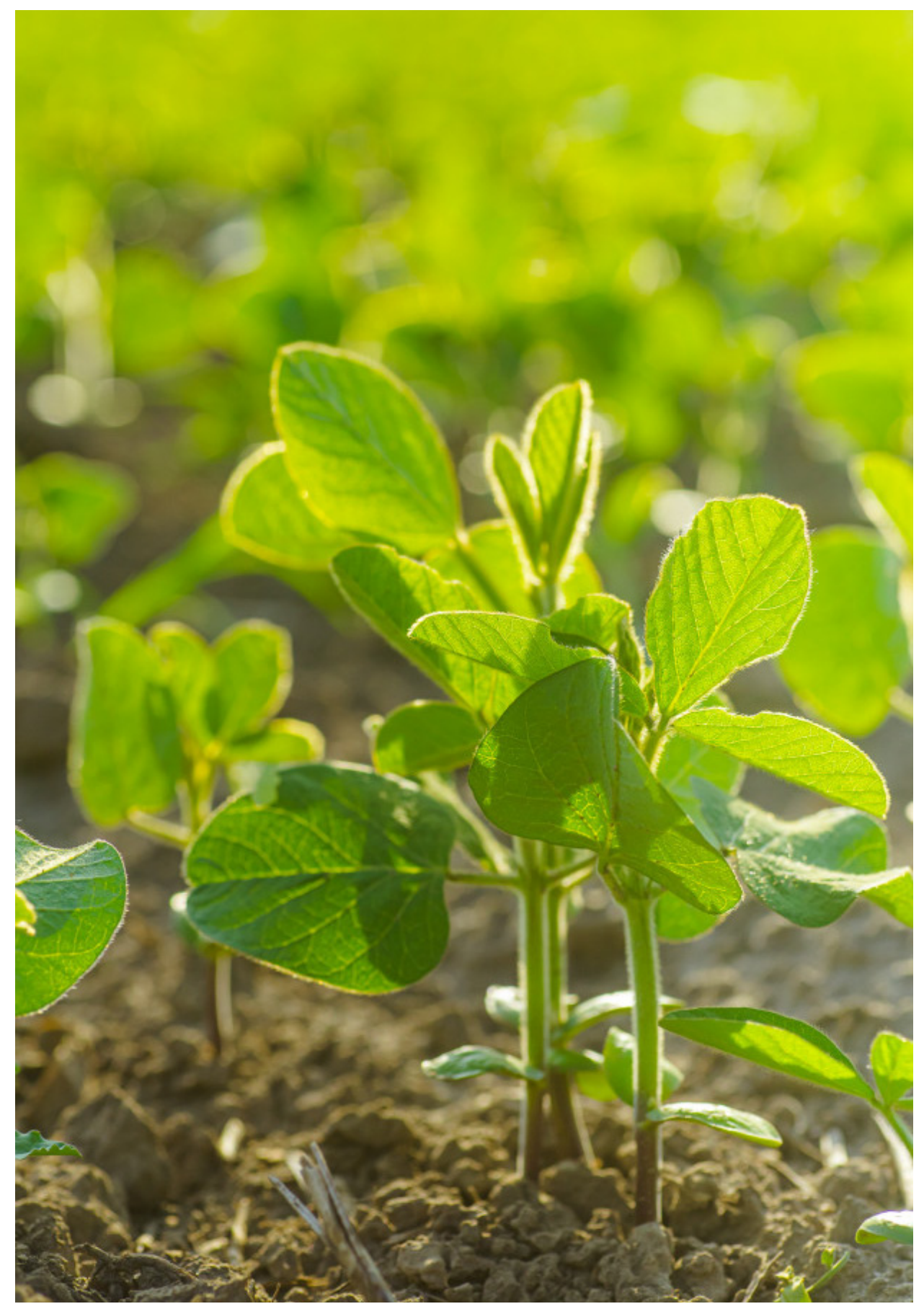

Рис. 1. Ростки сои. Источник: https://ru.freepik.com/premium-photo/glycine-max-soybean-soya-beansprout-growing-soybeans-on-an-industrial-scale_6346957.htm

2018 г. лидером по урожайности сои стали США, с показателями 32-35 ц/га обогнавшие Бразилию. В странах Европейского союза средняя урожайность сои составила в 2018 г. 28.1 ц/га. В России 2018 г. была получена средняя урожайность сои около 15.5 ц/га, по данным интернет-портала Федеральной службы государственной статистики http://www. gks.ru/. Повышение урожайности сои в значительной степени зависит от генетических факторов, что подчеркивает важность селекционной работы в этом направлении.

Род Glycine разделяется два подрода - Soja и Glycine - и представлен 18 травянистыми многолетними (Австралийский центр происхождения) и однолетними видами (ЮгоВосточный Азиатский (Китайский) центр происхождения). К последним относятся возделываемая соя G. $\max (2 n=4 x=$ $=40)$ и дикорастущая Glycine soja $(2 n=4 x=40)$, которые образуют подрод Sоја. Дикорастущая G. sоја является прямым предком возделываемой культурной сои G. max (Вавилов, 1926; Енкен, 1959; Жуковский, 1964; Hymowitz, 1970). G. soja используют в селекции для расширения генетического разнообразия культурной сои, в частности, в качестве донора 
агрономически полезных генов. Геном культурной сои относительно небольшой, если сравнивать с геномами других тетраплоидных видов растений, и составляет 1.1 млрд п.о. (Arumuganathan, Earle, 1991). Сравнительный анализ нуклеотидных последовательностей фрагментов ДНК сои показал, что геном сои - это мозаика палеополиплоидных участков с различной степенью консервативности и дивергированности (Schlueter et al., 2007). Примерно 75\% генов сои дуплицированы (Shoemaker et al., 1996). Судя по результатам исследований структурной изменчивости и экспрессии этих генов, эволюция гомеологичных районов шла неравномерно (Lin et al., 2010).

В настоящее время селекция сои направлена на улучшение агрономических качеств и повышение уровня пищевых и кормовых характеристик. Основные направления селекции:

- Повышение урожайности и сроков хранения семян.

- Улучшение состава семян.

- Повышение устойчивости к болезням, вредителям и нематодам.

- Повышение устойчивости к абиотическому стрессу.

- Повышение азотфиксирующей активности.

В настоящее время сою оценивают примерно по 30 качественным и количественным признакам, таким как количество семян в бобе, масса 100 семян, устойчивость к болезням и вредителям, стойкость к полеганию, содержание белка и масла в семенах, процент антипитательных веществ в семенах, опушенность плодов и многие другие (Абугалиева, 2013).

Методы селекции постоянно совершенствуются, что позволяет сокращать время, затрачиваемое на создание нового сорта. Так, использование методов маркерной и мутационной селекции позволили сократить период выхода на рынок новых сортов сои практически вдвое. Установлено, что многие селекционно ценные признаки сои контролируются несколькими генами, в таком случае изменчивость данного признака называется «количественной», «полигенной», «многофакторной» или «сложной». Индивидуальные локусы, задействованные в такой изменчивости, называются локусами количественных признаков (QTL - quantitative traits loci). Методом генетического картирования выявляют маркеры, тесно сцепленные с QTL или отдельными генами, участвующими в формировании изучаемого признака. Маркеры, сцепленные с QTL или конкретными генами, определяющими хозяйственно ценный признак, используют в маркер-ориентированной (МОС) или геномной селекции для ускорения селекционного процесса за счет отбора целевых генотипов на малой выборке растений еще на первых этапах селекции. Различие между МОС и геномной селекцией состоит в методах анализа растений, направленных на идентификацию ограниченного числа хозяйственно ценных генов в первом случае или на проведение полногеномного анализа генотипов по SNP (маркеры однонуклеотидного полиморфизма - ОНП) (Салина и др., 2016). В настоящем обзоре представлена оценка имеющегося в настоящее время молекулярного инструментария для сопровождения селекционных работ по сои с использованием технологий МОС и геномной селекции.

\section{Повышение урожайности} и сроков хранения семян

Масса семян

Масса семян (рис. 2) обычно выражается как масса 100 семян (100SW) и является одним из важнейших показателей урожайности сои. Показаны взаимосвязь массы и размера семян с их урожайностью, а также положительное влияние большей массы семян на прорастание и жизнеспособность.

В последние десятилетия проводились исследования по поиску генетических детерминант веса семян с привлечением различных популяций сои, позволяющих локализовать гены на хромосомах, и методов их анализа, в том числе полногеномный поиск ассоциаций (GWAS). Множество QTL с минорным эффектом было локализовано на всех 20 хромосомах сои, однако использование в селекции маркеров к таким QTL затруднено (Zhang et al., 2016; Liu et al., 2018). L. Yan c коллегами (2017) удалось обнаружить три главных QTL для массы 100 семян: один на 4-й хромосоме и два на 17-й. В других работах при различных условиях выращивания растений и использовании различных подходов идентификации QTL, определяющих вес семян, выявляется локус qSw17-1 на хромосоме 17, ассоциированный с маркером GMES4177, и swHCC2-1, ассоциированный с маркером Satt460 на хромосоме 6 (Han et al., 2012; Kato et al., 2014). Можно отметить, что маркеры, разработанные к ряду QTL локусов, которые стабильно воспроизводятся на всех используемых популяциях, перспективны для использования в маркер-ориентированной селекции.

Молекулярные механизмы контроля размеров семян сои изучены слабо, например, в сравнении с рисом, хотя за последние годы число работ по идентификации генов, определяющих этот признак, существенно увеличилось. Так, установлено, что ген In (узкий лист) связан с увеличением количества семян, а также с размером стручка и семени (Jeon et al., 2012). Показано, что аллель PP2C-1 (тип-2C фосфатазы белка) дикой сои линии ZYD7 способствует увеличению размера семени (Lu X. et al., 2017). Используя GWAS, L. Zhou c сотрудниками (2015) определили два гена-кандидата на хромосоме 11 и три гена-кандидата на хромосоме 16, связанных с размером семени. Три из этих пяти геновкандидатов показали более высокие уровни экспрессии во время развития семени. Один ген-кандидат, Glyma11g15480, гомологичен гену NOT2A арабидопсиса. Установлено, что Glyma11g15480 коэкспрессируется с 24 генами, гомологичными генам развития семян в Arabidopsis (Zhou Z. et al., 2015). В другом эксперименте GWAS J. Wang с коллегами обнаружили гены-кандидаты, влияющие на размер семени, а именно, ген Glyma11g03360, который гомологичен Os04g33740 (GIF1) риса, регулирующему заполнение и размер зерна, и Glyma11g03430, который гомологичен Os11g12740 (sp1) гену, контролирующему удлинение метелки и размер зерна (Wang et al., 2016).

Накопление данных по генам, определяющим вес и размер семян сои, способствует пониманию генетических механизмов формирования важных агрономических признаков и создает базу для интеграции молекулярных маркеров в селекцию этой культуры. 


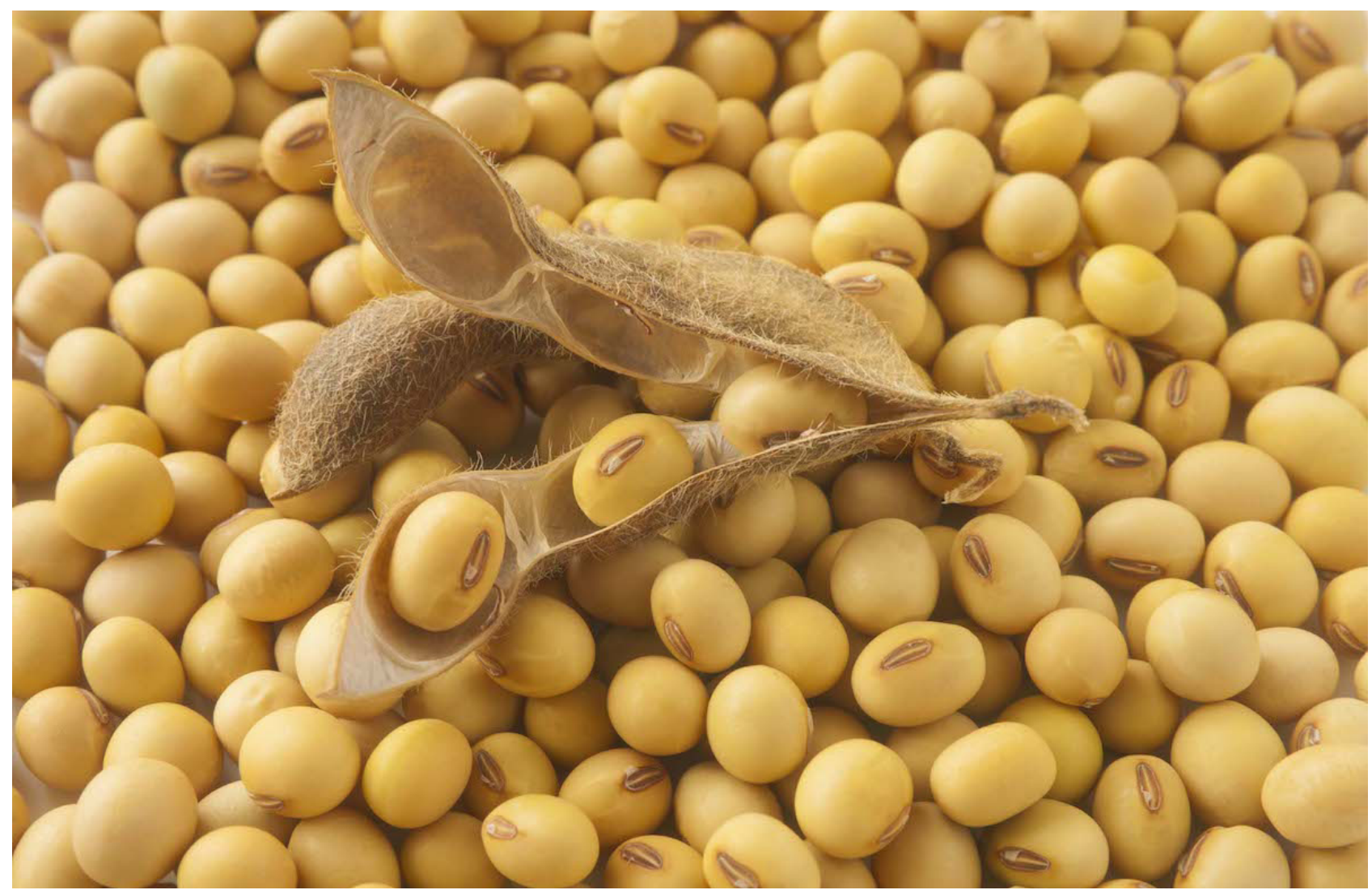

Рис. 2. Бобы сои. Источник: https://agroexpert.md/rus/agronomiya/top-10-gribnyh-bolezney-soi

Сроки хранения семян

Сроки хранения семян сои - основная проблема во влажных регионах, климат которых негативно влияет на качество посевных семян (Tripathi, Khare, 2016). В физиологической зрелости семя достигает своего максимального потенциала для прорастания и энергии. На сроки хранения семян сои влияют такие факторы, как размер семени, твердость, толщина оболочки семени, содержание масла и другие. L. Sun c коллегами (2015) выделили четыре различных SSR-маркера, Satt538, Satt600, Satt434 и Satt285, которые маркируют генные локусы, определяющие сроки хранения семян сои, и находятся в соответствующих группах сцепления A2, D1b, H и J (табл. 1).

J. Hosamani и др. (2013) идентифицировали три SSRмаркера, Satt371, Satt453 и Satt618, сцепленных с генами, определяющими цвет семенной кожуры и, возможно, влияющими на сроки хранения семян (см. табл. 1).

\section{Твердосемянность}

Умеренный уровень непроницаемости семенной оболочки, или твердосемянность (hard-seededness), важен для сохранения жизнеспособности семян в тропических условиях. Для этого признака B. Zhang с коллегами (2008) определили QTL на хромосоме 2; позже он был подтвержден L. Sun c coавторами (2015) и назван ими GmHs1-1. Исследователи ограничили этот QTL районом в 22-kb, который содержал два гена - Glyma02g43700.1 и Glyma02g43710.1 (см. табл. 1). Секвенирование этих генов позволило обнаружить одиночную замену нуклеотида (C>T) в 8-м экзоне гена Glyma02g43700.1. Эта замена приводила к замещению треонина метионином. Эксперименты с генетической трансформацией геном Glyma02g43700.1 подтвердили, что именно этот ген и является локусом GmHs1-1. Возможно, ген Glyma02g43700.1 кодирует кальциневрин-подобный трансмембранный белок металлофосфоэстеразу (Sun et al., 2015).

\section{Растрескивание семени}

Растрескивание ухудшает внешний вид семени, что снижает рыночную стоимость семян. Кроме того, оно создает возможность беспрепятственного проникновения патогенов внутрь семени. Выделяют два типа растрескивания в сое: беспорядочные трещины и решетчатые. T. Nakamura c coтрудниками (2003) предположили, что решетчатым растрескиванием управляет, прежде всего, ген SoyPRPI богатого пролином белка клеточной стенки. Однако проведенные ими исследования показали, что основной ген, влияющий на решетчатое растрескивание, не коррелирует с SoyPRPI, a SSR-маркер Satt264, тесно сцепленный с локусом SoyPRPI, незначительно связан с индексом растрескивания (см. табл. 1).

\section{Раскрытие стручка}

Степень потери урожая из-за раскрытия стручка (рис. 3) может колебаться от 34 до 100 \%. На раскрытие стручка могут влиять морфологическая архитектура растения, анатомическая структура стручка, химический состав его оболочки, 


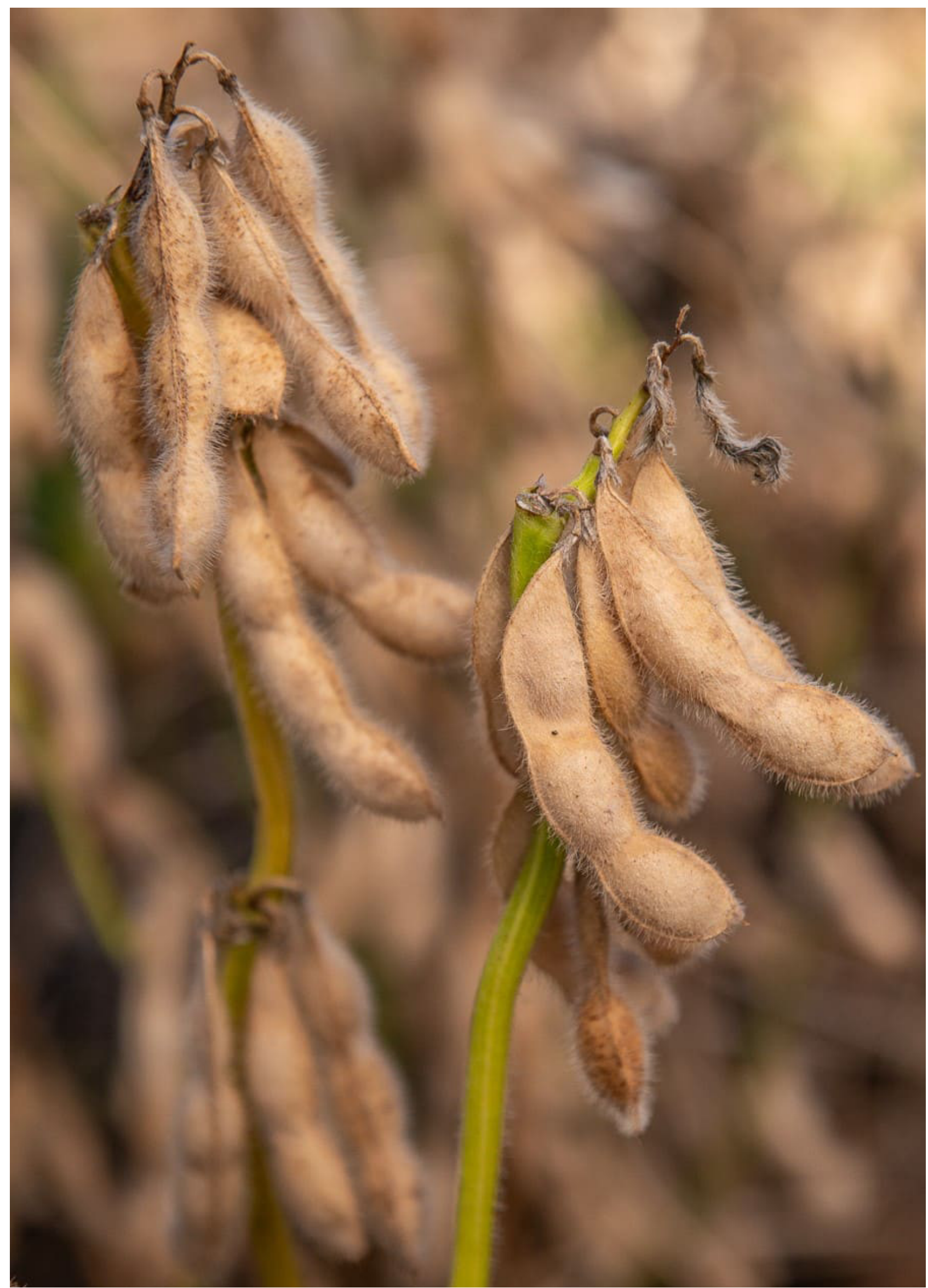

Рис. 3. Стручки сои. Источник: https://yugagro.org/Stati/uborka-soi 
Таблица 1. SSR-маркеры, связанные с характеристиками семян сои

Table 1. SSR-markers related to soybean grain characteristics

\begin{tabular}{|c|c|c|c|c|}
\hline Признак & Локус & Группа сцепления & Связанные маркеры & Ссылки \\
\hline Сроки хранения семян & - & $\begin{array}{l}J(X p 9) \\
H(X p 12)\end{array}$ & $\begin{array}{l}\text { Satt285 } \\
\text { Satt434 }\end{array}$ & Singh et al., 2008 \\
\hline $\begin{array}{l}\text { Связь сроков хранения семян со цветом } \\
\text { семенной кожуры }\end{array}$ & - & $\begin{array}{l}\text { C2 (Xp 6) } \\
\text { B1 (Xp 11) } \\
\text { M (Xp 7) }\end{array}$ & $\begin{array}{l}\text { Satt371 } \\
\text { Satt453 } \\
\text { Satt618 }\end{array}$ & Hosamani et al., 2013 \\
\hline Проницаемость семенной оболочки & - & $\begin{array}{l}\text { H (Xp 12) } \\
\text { A2 (Xp 8) } \\
\text { C2 (Xp 6) } \\
\text { E (Xp 15) }\end{array}$ & $\begin{array}{l}\text { Satt434 } \\
\text { Satt538 } \\
\text { Satt281 } \\
\text { Satt598 }\end{array}$ & Sun et al., 2015 \\
\hline Растрескивание семени & SoyPRPI & $\mathrm{K}$ & Satt264 & Nakamura et al., 2003 \\
\hline
\end{tabular}

условия окружающей среды и прочее. Главный QTL для pacкрытия стручка, qPDH1, расположен на хромосоме 16 (группа сцепления J) между маркерами SSR, Sat_093 и Sat_366. Позднее, при более точном картировании, были выявлены маркеры SRM0, SRM1 и SRM2 для признака устойчивости к раскрытию стручка (Suzuki et al., 2010).

H. Funatsuki с коллегами (2014) определили содержащийся в локусе ген Glyma16g25580.1 (Pdh1), который кодирует dirigent-подобный белок, который увеличивает скручивание высохших створок стручка и способствует его раскрытию. В генотипе, устойчивом к раскрытию стручка, был обнаружен дефектный ген $p d h 1$, имеющий преждевременный стоп-кодон (Funatsuki et al., 2014). Функциональные маркеры, разработанные на основе нонсенс-мутации, могут быть использованы для селекции (табл. 2).

\section{Переход к фазе цветения}

Соя - растение короткого дня, то есть цветение (рис. 4) начинается при сокращении светового дня до определенной продолжительности. При перенесении зоны возделывания в высокие широты с более продолжительным летним днем у большинства сортов цветение задерживается и бобы не успевают созреть до наступления холодов (Kumawat et al., 2016). Перемещение большинства генотипов ближе к экватору значительно сокращает вегетационный период, что резко снижает продуктивность растений. Выращивание сои на разных географических широтах требует использования разных аллелей генов, контролирующих переход к фазе цветения, что позволяет максимально точно адаптировать генотипы к локальным условиям произрастания (Kumawat et al., 2016).

Генетические факторы, инициирующие переход растения от вегетативного развития к генеративному, были изучены для многих растений с привлечением данных, полученных на модельном объекте Arabidopsis thaliana (apaбидопсис). На переход растений к цветению влияют различные внешние и внутренние факторы (Киселёва, Салина, 2018). Можно выделить такие внутренние факторы, как циркадные ритмы, углеводный статус, старение, фитогормоны, которые оказывают влияние на переход растения к фазе цветения. К внешним воздействиям относятся фотопериод, яровизация (воздействие низких температур) и температу- ра окружающей среды. Определено несколько интегральных генов в сигнальных путях, реагирующих на внутренние и внешние факторы. Это гены FT (FLOWERING LOCUS T) и SOC1 (SUPPRESSOR OF OVEREXPRESSION OF CONSTANS1), которые активируют гены, участвующие в формировании цветка: (LEAFY), AP1 (APETALA1), SEP3 (SEPALLATA3) и FUL (FRUITFULL).

F.V. Owen (1927) обнаружил два основных гена, ассоциированных со временем созревания, и обозначил их как $E$ и е. В настоящее время известно 11 Е генов (E1-E11), локализованных на различных участках хромосом сои (Zhang et al., 2017; Wang et al., 2019). Кроме того, у каждого гена еще иногда описывают различные аллельные варианты. Так, например, у гена E1 есть два аллельных варианта E1 La и E1Lb, расположенных в гомологичных районах хромосом и имеющих более 90\% сходства по структуре белка с 11 .

Наиболее детально к настоящему моменту проведен молекулярный анализ локусов, содержащих гены $E 1, E 2, E 3, E 4$ и $E 9$, для которых выявлены механизмы их влияния на переход растения к фазе цветения.

Локус Е1 играет главную роль в фотопериодической регуляции цветения. Z. Хіа с сотрудниками ограничили локус E1 единственным геном - Glyma.06G207800), который кодирует, вероятно, фактор транскрипции, содержащий В3 домен с предполагаемым двусторонним NLS (nuclear localization signal) и ДНК-связывающей структурой на С-конце (см. табл. 2). Его дисфункциональные формы интенсивно отбирали в высокоширотных районах Азии и Северной Америки (Xia et al., 2012; Zhou et al., 2015). E1, также как его аллельные варианты E1La (Glyma.04G156400) и E1Lb (Glyma.04G143300), сильно репрессируются в условиях короткого дня и индуцируются в условиях длинного дня (Xia et al., 2012; Xu et al., 2015; Zhai et al., 2015). Теневая фаза в условиях короткого дня требуется для их репрессии. Прерывание теневой фазы приводит к дерепрессии и задерживает цветение (Xu et al., 2015). Растения с ранним цветением имеют мутацию в промоторе $E 1$, которая предотвращает экспрессию $E 1$ (Xia et al., 2012). Показано, что сайленсинг генов E1La и E1Lb увеличивает экспрессию FТ-генов и вызывает раннее цветение (Xu et al., 2015). Локус E2 содержит GIGANTEA (GmGla, Glyma.10G221500), ортолог Gl арабидопсиса (см. табл. 2). 
Таблица 2. Характеристика маркеров к генам, определяющим хозяйственно ценные признаки сои Table 2. Characterization of markers to genes determining economic valuable traits of soybean

\begin{tabular}{|c|c|c|c|c|c|}
\hline Признак & $\begin{array}{l}\text { Ген/ } \\
\text { аллель }\end{array}$ & Тип маркера & $\begin{array}{l}\text { Размеры ДНК-фрагментов } \\
\text { для маркируемого аллеля гена, bp }\end{array}$ & $\begin{array}{l}\text { SNP/ } \\
\text { Indel аллель }\end{array}$ & Ссылки \\
\hline \multirow[t]{12}{*}{$\begin{array}{l}\text { Цветение } \\
\text { и созревание }\end{array}$} & $e 1-f_{s} / e 1-n l$ & CAPS $(H i n f l)$ & $\begin{array}{l}\text { E1/e1-as: } 186+36 \\
\text { E1-fs: } 136+46+36 \\
\text { E1-nl: No amplification }\end{array}$ & $A /-$ & Xia et al., 2012 \\
\hline & E1-as & dCAPS (Taq I) & $\begin{array}{l}\text { E1/e1-fs/e1-nl: } 444 / 443 \\
\text { E1-as: } 413+31\end{array}$ & $\mathrm{C} / \mathrm{G}$ & Xia et al., 2012 \\
\hline & e2 & dCAPS (Dra l) & $\begin{array}{l}\text { E2: } 110 \\
\text { e2: } 27+83\end{array}$ & $A / T$ & Watanabe et al., 2011 \\
\hline & e3-tr & AFLP & $\begin{array}{l}\text { E3-Misuzudaizu: } 1339 \text { E3-Harasoy: } 558 \\
\text { e3-tr: } 275\end{array}$ & - & Watanabe et al., 2009 \\
\hline & e3-fs & CAPS (Ale I) & $\begin{array}{l}E 3: 552+206 \\
e 3-f s: 759\end{array}$ & $-/ \mathrm{T}$ & Xia et al., 2012 \\
\hline & e3-ns & dCAPS (Mfel) & $\begin{array}{l}\text { E3: } 163 \\
\text { e3: } 140+23\end{array}$ & $\mathrm{C} / \mathrm{T}$ & Xia et al., 2012 \\
\hline & e4-oto & CAPS (Sacl) & $\begin{array}{l}E 4: 535 \\
e 4: 439+96\end{array}$ & G/- & Tsubokura et al., 2013 \\
\hline & e4-tsu & dCAPS (Eco RV) & $\begin{array}{l}\text { E4: } 355 \\
\text { e4-tsu: } 332+23\end{array}$ & $\mathrm{~T} /-$ & Tsubokura et al., 2013 \\
\hline & e4-kam & CAPS $(A f I I I)$ & $\begin{array}{l}\text { E4: } 494 \\
\text { e4-kam: } 286+208\end{array}$ & G/- & Tsubokura et al., 2013 \\
\hline & e4-kes & CAPS (BSP HI) & $\begin{array}{l}\text { E4: } 494 \\
\text { e4-kes: } 399+95\end{array}$ & $A /-$ & Tsubokura et al., 2013 \\
\hline & e4-SORE-I & AFLP & $\begin{array}{l}\text { E4: } 1229 \\
\text { e4-SORE-I: } 837\end{array}$ & - & Liu et al., 2008 \\
\hline & e9-SORE-I & AFLP & - & - & Zhao et al., 2016 \\
\hline $\begin{array}{l}\text { Раскрытие } \\
\text { стручка }\end{array}$ & Pdh1 & CAPS (Nhe l) & $\begin{array}{l}\text { Pdh1: } 125 \\
\text { pdh1: } 76+49\end{array}$ & $A / T$ & Funatsuki et al., 2014 \\
\hline \multirow{3}{*}{$\begin{array}{l}\text { Содержание } \\
\text { олеиновой } \\
\text { кислоты }\end{array}$} & FAD2-1A & GC -Tail assay & - & $\mathrm{G} / \mathrm{A}$ & Dierking, Bilyeu, 2009 \\
\hline & FAD2-1A & $\begin{array}{l}\text { Simple probe } \\
\text { assay }\end{array}$ & - & $A /-$ & Pham et al., 2011 \\
\hline & $F A D 2-1 B$ & $\begin{array}{l}\text { Simple probe } \\
\text { assay }\end{array}$ & - & $\begin{array}{l}\text { T/C (In Bold) } \\
\text { C/G (Under- } \\
\text { lined) }\end{array}$ & Pham et al., 2010 \\
\hline $\begin{array}{l}\text { Содержание } \\
\text { раффинозы }\end{array}$ & $R S 2$ & GC-Tail assay & - & $\mathrm{C} / \mathrm{T}$ & Dierking, Bilyeu, 2009 \\
\hline $\begin{array}{l}\text { Ингибитор } \\
\text { трипсина } \\
\text { Кунитса }\end{array}$ & $K t i$ & PCR & kti: 420 & - & $\begin{array}{l}\text { Alves de Moraes et al., } \\
2006\end{array}$ \\
\hline
\end{tabular}


Таблица 2 (окончание)

Table 2 (end)

\begin{tabular}{|c|c|c|c|c|c|}
\hline \multirow[t]{6}{*}{ Аромат } & $G m B A D H 2-A 2$ & SNAP & $\begin{array}{l}\text { Wild type } \\
\text { Fragrant: } 126\end{array}$ & $\mathrm{G} / \mathrm{A}$ & $\begin{array}{l}\text { Juwattanasomran et al., } \\
2011\end{array}$ \\
\hline & $\begin{array}{l}\text { GmBADH2- } \\
\text { EX10 }\end{array}$ & Indel & $\begin{array}{l}\text { Wild type: } 174 \\
\text { Fragrant: } 172\end{array}$ & - & $\begin{array}{l}\text { Juwattanasomran et al., } \\
2012\end{array}$ \\
\hline & GmBADH2-G1 & SNAP & Wild type - Fragant 125 & - & $\begin{array}{l}\text { Juwattanasomran et al., } \\
2011\end{array}$ \\
\hline & GmBADH2-G2 & SNAP & Wild type - Fragant 126 & - & $\begin{array}{l}\text { Juwattanasomran et al., } \\
2011\end{array}$ \\
\hline & GmBADH2-G3 & SNAP & Wild type - Fragant 129 & - & $\begin{array}{l}\text { Juwattanasomran et al., } \\
2011\end{array}$ \\
\hline & GmBADH2-A1 & SNAP & Wild type -Fragant 126 & - & $\begin{array}{l}\text { Juwattanasomran et al., } \\
2011\end{array}$ \\
\hline \multirow{5}{*}{$\begin{array}{l}\text { Соевая } \\
\text { цистообра- } \\
\text { зующая } \\
\text { нематода }\end{array}$} & Rhg1-2 & KASPar & - & $\mathrm{C} / \mathrm{G}$ & Kadam et al., 2016 \\
\hline & Rhg1-5 & KASPar & - & $\mathrm{C} / \mathrm{G}$ & Kadam et al., 2016 \\
\hline & Rhg4-3 & KASPar & - & $\mathrm{A} / \mathrm{T}$ & Kadam et al., 2016 \\
\hline & Rhg4-5 & KASPar & - & $\mathrm{C} / \mathrm{G}$ & Kadam et al., 2016 \\
\hline & Rhg1 & Taqman assay & - & CNV & Kadam et al., 2016 \\
\hline \multirow{3}{*}{$\begin{array}{l}\text { Солеустой- } \\
\text { чивость }\end{array}$} & $M 1$ & KASPar & - & $\mathrm{G} / \mathrm{C}$ & Patil et al., 2016 \\
\hline & M4 & KASPar & - & $\mathrm{C} / \mathrm{G}$ & Patil et al., 2016 \\
\hline & M6 & KASPar & - & $\mathrm{G} / \mathrm{T}$ & Patil et al., 2016 \\
\hline
\end{tabular}

B coe GmGla задерживает инициирование цветения только в условиях длинного дня (de Montaigu et al., 2015).

Локусы E3 и E4 включают два гомолога РhyA (фитохром A) - GmPhyA3 и GmPhyA2 соответственно. Растения, несущие аллели локуса $E 3$, содержащие замену аминокислоты глицин на аргинин или делецию 40 bр в первом экзоне, показывают ускорение цветения. PhyA2, кодируемый E4, тоже регулирует цветение (см. табл. 2). Аллель GmPhyA2 с ретротранспозоном в первом интроне приводит к раннему цветению. GmPhyA2 также регулирует вегетативную фазу развития сои. E3 и E4 влияют на экспрессию генов $E 1$ и его гомологов.

Локус E9 содержит ген FT2a (Glyma.16G150700) (см. табл. 2). Вставка транспозона в первом интроне $F T 2 a$ уменьшает уровень экспрессии FT2a, что приводит к задержке цветения (Zhao et al., 2016). Этот аллель распространен в культурах северной Японии с нулевыми аллелями в локусах $E 1, E 3$ и $E 4$, уменьшенная экспрессия FT2a позволяет продлить вегетативную стадию, чтобы увеличить урожай (Zhao et al., 2016).

Комбинируя сочетаниями различных аллелей генов Е1E11, можно создавать необходимые варианты сроков цветения и созревания. Маркеры, которые можно привлекать к маркер-ориентированной селекции для регулирования фазы перехода к цветению у сои, приведены в табл. 2 .
Еще один интересный ген GMELF3 недавно был идентифицирован двумя независимыми группами исследователей в локусе J (long-juvenile), влияющем на продление вегетативной стадии развития сои (Lu X. et al., 2017; Yue et al., 2017). Показано, что GmELF3 взаимодействует с промотором E1 и подавляет его транскрипцию, чтобы ускорить цветение в условиях короткого дня (Qi et al., 2016). Дисфункция GmELF3 усиливает экспрессию $E 1$ и продляет вегетативную стадию. Многие дисфункциональные аллели GMELF3 были выделены и использованы для выведения элитных сортов сои в тропических условиях (Lu S. et al., 2017; Yue et al., 2017).

\section{Состав семян}

\section{Содержание белка}

Поскольку соя - одновременно и белковая, и масличная культура, ее селекция имеет два противоположных направления: получение сортов с более высоким содержанием белка и более высоким содержанием масла. Существует отрицательная корреляция между содержанием белка и масла у сои (Hyten et al., 2004). Большое внимание уделяется качественному составу белковой фракции, который зависит не только от генотипа, но и от условий выращивания расте- 


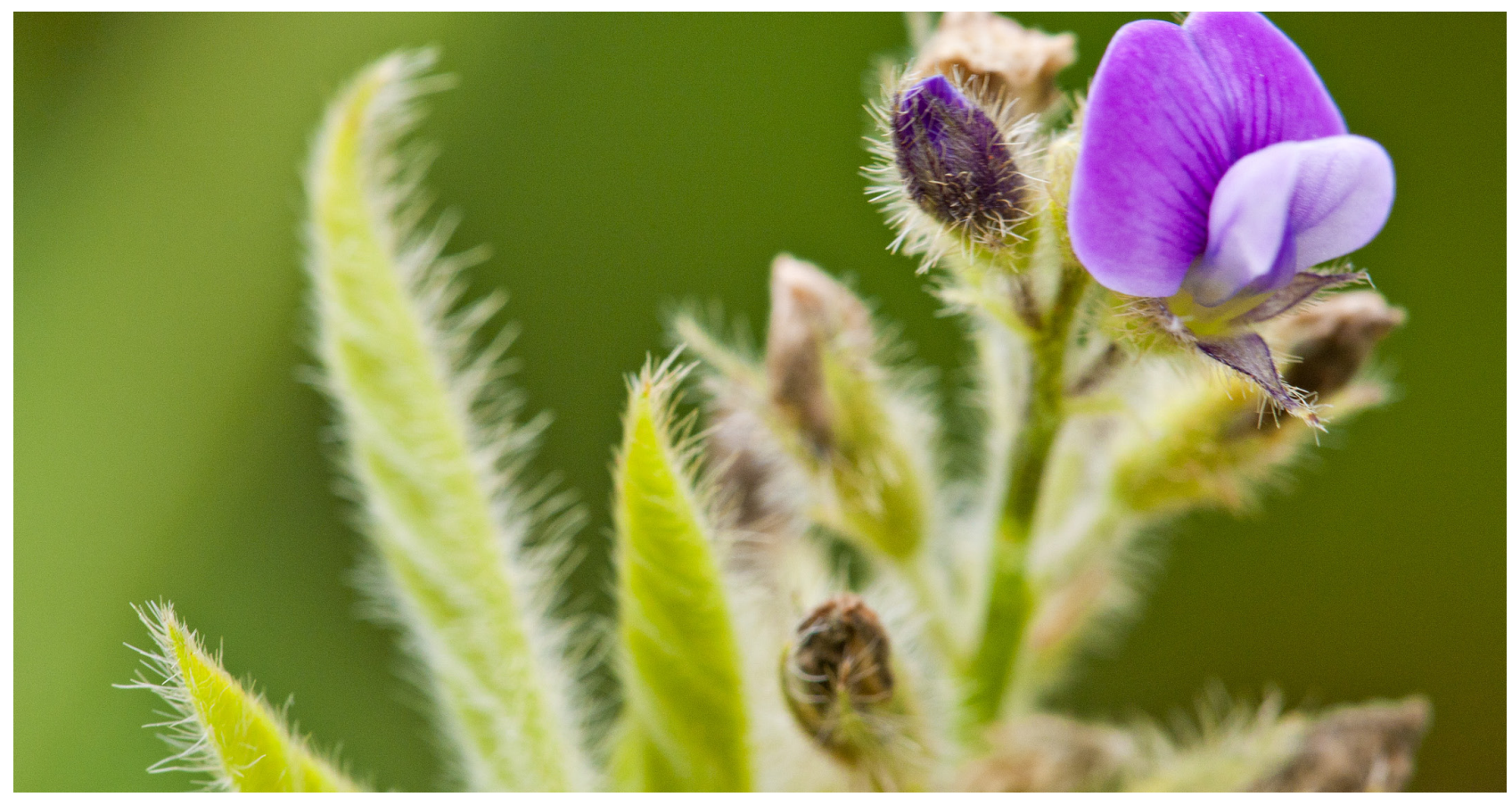

Рис. 4. Цветок сои. Источник: https://www.agro.basf.ru/ru/Crop-Solutions/Crop-group-detail_14642.html

ний. Естественно, особый интерес исследователей направлен на способность растений формировать высокое содержание белка в различных экологических условиях (Qi et al., 2016). Известно, что содержание в семенах белка и масла подвержено модификационной изменчивости, причем влияние среды на масличность значительно менее существенно, чем на белок (Bellaloui et al., 2011).

На основании базы данных генетических карт бобовых (The Legume Information systems) известно большое количество QTL по признаку белковости у сои. Основные сводные данные аккумулируются на сайте SoyBase and the Soybean Breeder's Toolbox (Grant et al., 2010). Но продолжаются работы по поиску и валидации QTL, связанных с содержанием белка в сое, не зависящим от условий окружающей среды (Qi et al., 2016). Интересно, что были обнаружены три пары QTL с эпистатическим эффектом, одна пара на хромосоме 19, вторая на хромосомах 9 и 18, третья пара - на хромосомах 2 и 19, которые контролируют примерно 50\% вариаций содержания белка в сое при различных условиях выращивания (Qi et al., 2016).

Обнаружено множество QTL, влияющих на содержание белка в семенах. Наиболее интересны локусы, расположенные на хромосоме 20, они были обнаружены при использовании разнообразных картирующих популяций, различающих как по исходным родительским сортам, включенных в скрещивание, так и по генетической структуре анализируемых поколений (F2, поколения беккроссов, рекомбинантные инбредные линии и т. д.). Были идентифицированы и охарактеризованы гены, находящиеся в этих локусах, например гены, кодирующие потенциальный белок-регулятор семейства Mov34-1, белок теплового шока Hsp22.5 и АТР-синтазу. Несмотря на большое количество проблем, таких как нестабильность белка при понижении температуры, отрицательное влияние повышенного содержания белка на урожайность, плеотропные эффекты и прочие, работы, направленные на повышение содержания белка в семенах con, в настоящее время весьма перспективны (Patil et al., 2017).

Содержание белка в сое приблизительно 35-42\%, по коэффициенту седиментации белки можно разделить на фракции 2S, 7S, 11S и 15S. Основные запасные белки - глобулины $11 \mathrm{~S}$ и 7S, которые составляют от общего запасного белка 40 и 30\% соответственно. Фракция $11 \mathrm{~S}$ - это глицинин, тогда как основную часть 7S-фракции составляет $\beta$-конглицинин (Panthee et al., 2006; Ma et al., 2016).

Глицинин обычно существует в форме гексамера $360 \mathrm{kDa}$, который состоит из кислых и основных субъединиц, $\beta$-конглицинин обычно представляет собой тример, приблизительно $180 \mathrm{kDa}$, включающий в себя a-, $\mathrm{a}^{\prime}-$ и $\beta$-субъединицы, которые кодируются предположительно 15 генами (CG1-CG15). Из-за отсутствия содержащих серу аминокислот $\beta$-субъединица не представляет особой питательной ценности, кроме того глицинин содержит в 3-4 раза

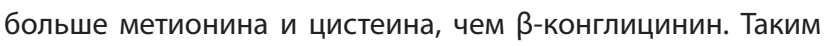
образом, увеличивая наработку фракции 11S и уменьшая накопление фракции 7S, можно улучшить пищевое качество сои. Показано, что соотношение этих фракций влияет на качество тофу и соевого молока, а также важно для кормопроизводства. Установлено также, что фракция $11 \mathrm{~S}$ может быть использована как естественный консервант в сыром коровьем молоке (Panthee et al., 2006; Ma et al., 2016).

Y. Ма с коллегами (2016) картировали 35 QTL, связанных с фракциями 7S и 11S, отношением 11S/7S и суммой 11S+7S; о некоторых сообщали ранее другие исследователи. Авторы определили пять крупнейших геномных локусов, расположенных на хромосомах 1, 4, 6, 10 и 20 и перекрывающихся 
Таблица 3. QTL для фракций $11 \mathrm{~S}$ и $7 \mathrm{~S}$

Table 3. QTL for $11 \mathrm{~S}$ and $7 \mathrm{~S}$ fractions

\begin{tabular}{|c|c|c|c|c|c|}
\hline Признак & QTL & Хромосома & Маркерный интервал & Связанные QTL & Источник \\
\hline $11 \mathrm{~S}$ & q11s-1-1 & 1 & sat_343-sat_345 & - & $\begin{array}{l}\text { Csanadi et al., } 2001 \\
\text { Pandurangan et al., } 2012\end{array}$ \\
\hline $11 \mathrm{~S}$ & q11s-1-2 & 1 & satt468-sat_160 & $\begin{array}{l}\text { seed protein } 31-1 \\
\text { seed protein } 31-2 \\
\text { seed protein } 31-4 \\
\text { seed protein } 13-1\end{array}$ & $\begin{array}{l}\text { Csanadi et al., } 2001 \\
\text { Pandurangan et al., } 2012\end{array}$ \\
\hline $11 \mathrm{~S}$ & q11S-4-1 & 4 & satt646-satt139 & $\begin{array}{l}\text { seed Trp 1-2 } \\
\text { seed Ser 1-2 }\end{array}$ & Panthee et al., 2006 \\
\hline $11 \mathrm{~S}$ & q11S-6-1 & 6 & satt681-satt227 & - & Panthee et al., 2006 \\
\hline $11 \mathrm{~S}$ & q11S-6-2 & 6 & satt286-satt365 & - & Panthee et al., 2006 \\
\hline $11 \mathrm{~S}$ & & & satt286-satt365 & - & Panthee et al., 2006 \\
\hline $11 \mathrm{~S}$ & & & satt286-satt365 & - & Panthee et al., 2006 \\
\hline $11 \mathrm{~S}$ & q11S-10-1 & 10 & sat_303-sat_318 & - & Panthee et al., 2006 \\
\hline $11 \mathrm{~S}$ & q11S-20-1 & 20 & $\begin{array}{l}\text { satt102-sat_419 } \\
\text { satt440-satt102 } \\
\text { satt102-sat_419 }\end{array}$ & - & Panthee et al., 2006 \\
\hline $7 S$ & q7S-1-1 & 1 & satt468-sat_160 & $\begin{array}{l}\text { seed protein } 31-1 \\
\text { seed protein } 31-2 \\
\text { seed protein } 31-4 \\
\text { seed protein } 13-1\end{array}$ & $\begin{array}{l}\text { Csanadi et al., } 2001 \\
\text { Pandurangan et al., } 2012\end{array}$ \\
\hline $7 S$ & $q 75-1-2$ & 1 & sat_345-satt436 & - & $\begin{array}{l}\text { Csanadi et al., } 2001 \\
\text { Pandurangan et al., } 2012\end{array}$ \\
\hline $7 S$ & q7S-17-1 & 17 & sat_222-satt464 & $\begin{array}{l}\text { seed glycinin 1-1 } \\
\text { seed conglycinin 1-1 }\end{array}$ & Panthee et al., 2004 \\
\hline $7 S$ & q7S-17-2 & 17 & satt135-satt669 & $\begin{array}{l}\text { seed Leu 1-3 } \\
\text { seed Met plus Cys 1-1 } \\
\text { seed glycitein 8-8 }\end{array}$ & Panthee et al., 2006 \\
\hline $7 S$ & q7S-19-1 & 19 & sat_187-satt278 & $\begin{array}{l}\text { seed Thr 1-2 } \\
\text { seed Val 1-4 } \\
\text { seed Ala 1-6 }\end{array}$ & Panthee et al., 2006 \\
\hline $7 S$ & q7S-19-2 & 19 & $\begin{array}{l}\text { sat_245-satt373 } \\
\text { sat_245-satt373 }\end{array}$ & seed protein $16-2$ & Chapman et al., 2003 \\
\hline $7 S$ & q7S-20-1 & 20 & sat_419-satt623 & - & Chapman et al., 2003 \\
\hline
\end{tabular}

с несколькими QTL для различных черт, они также обнаружили шесть эпистатических QTL (табл. 3).

M. Kim с сотрудниками (2016) сообщают об удобном для применения в селекции QTL-маркере высокого содержания белка. Этот маркер расположен в интервале размером 535 kb между маркерами BARCSOYSSR_15_0161 и BARCSOYSSR_15_0194 на хромосоме 15. Z. Qi с коллегами (2016) идентифицировали главные QTL для содержания белка в семенах сои на хромосомах 3, 6, 7, 13 и 15. Некоторые из этих QTL демонстрируют эпистатические взаимодействия.

Большое значение для определения качества соевых белков имеет их аминокислотный состав. Известно, что содержание серосодержащих аминокислот метионина (Met) и цистеина (Суs) в соевых белках низкое, потому селекционная работа, направленная на повышение их концентрации в соевых бобах, очень важна. D.R. Pantheе и др. (2006) идентифицировали QTLs, ассоциированные с содержанием Cys и Met (2006). Четыре QTL, маркируемые микросателлитами Satt235, Satt252, Satt427 и Satt436, распределенными по хромосомам 1, 13 и 18, коррелировали с содержанием Суs. Еще три QTL, сцепленные с молекулярными маркерами Satt252, Satt564 и Satt590, распределенными по хромосомам 13, 18 и 7, были ассоциированы с концентрацией Met в семенах сои. С генами, влияющими на содержание и цистеина и метионина, сцеплены маркеры Satt143 и Satt495 на хромосоме 7, а также Satt252 на хромосоме 13. 


\section{Содержание масла}

Семена сои содержат жирные кислоты, их содержание составляет примерно 20\% массы семени. Масло семян сои состоит из пяти основных жирных кислот: пальмитиновой, стеариновой, олеиновой, линолевой и линоленовой (Xie et al., 2012). Низкая доля пальмитиновой кислоты в соевом масле желательна для уменьшения риска сердечно-сосудистых заболеваний (Akond et al., 2014). Диета с высоким содержанием олеиновой кислоты снижает показатели холестерина. Соевое масло также используют для производства биодизельного топлива. Высокий уровень олеиновой кислоты повышает окислительную устойчивость биодизеля.

Высокое содержание линоленовых и линолевых кислот желательно для увеличения энергосодержания биодизеля (Akond et al., 2014). Человеческий организм не способен синтезировать линолевую и линоленовую кислоты, и соя может быть ценным источником этих жирных кислот. Однако линоленовая кислота ухудшает качество масла сои из-за способности легко окисляться при помощи фермента, что ухудшает аромат масла и значительно сокращает сроки хранения.

M.J. Monteros с коллегами (2008) обнаружили 6 QTL, влияющих на содержание олеиновой кислоты: на хромосоме 5 (рядом с Satt211), хромосоме 17 (рядом с Satt389), хромосоме 18 (рядом с Satt394 и Satt191), хромосоме 19 (рядом c Satt418 и Satt561). A.-T. Pham с сотрудниками изучали мутантные аллели в двух генах FAD2-1A и FAD2-1B омега-6 десатуразы жирных кислот, участвующей в десатурировании олеиновой кислоты в линолевую (см. табл. 2).

Наличие миссенс-мутантных аллелей гена FAD2-1B увеличивало содержание олеиновой кислоты, но ее высокое содержание наблюдалось только при наличии мутантных аллелей по обоим генам FAD2-1A и FAD2-1B (Pham et al., 2010). Была также обнаружена миссенс-мутация в гене десатуразы омега-6 жирных кислот FAD2-1A, которая приводила к повышению содержания олеиновой кислоты и к снижению - линолевой (Dierking, Bilyeu, 2009). Интересно, что гены FAD2-1A и FAD2-1B картированы на хромосомах 10 и 20, а их изоформы FAD2-2A и FAD2-2B - на хромосоме 19 (Bachlava et al., 2008).

D. Хie c коллегами (2012) нашли три интересные с точки зрения MOC аллели гена QLNB, связанные с низким содержанием линоленовой кислоты, на хромосоме 14: QLNB2_1 (рядом с Satt726), QLNB2_2 (рядом с Fad3a-4) и QLND1b_1 (рядом с Satt701).

M. Akond с соавторами (2014) идентифицировали 11 QTL, влияющих на содержание масла в семенах, на хромосомах $3,5,9,13,14 ;$ и 16 QTL для пяти основных жирных кислот на хромосомах 3, 13, 14, 15, 16 и 18.

K 2017 г. были картированы более ста QTL, связанных с содержанием масла в семенах сои, а на участках, где находятся эти QTL, идентифицированы 14 генов, аллели которых контролируют различия по содержанию жирных кислот (Fang et al., 2017).

\section{Липоксигеназа}

Качество соевого масла зависит от содержания в нем липоксигеназы. Она катализирует окисление ненасыщен- ных жирных кислот, что вызывает специфический привкус сырой сои (Вишнякова и др., 2017). Семена сои считаются самым богатым природным источником липоксигеназы. Известны три изофермента этого вещества, за неприятный привкус ответственна, в основном, липоксигеназа 2. Растения с низким содержанием липоксигеназы используют для селекции овощной сои. Известны три нуль-аллеля для трех изоферментов. В нуль-аллеле гена липоксигеназы 1 (Lx1) имеется делеция 74bp в 8 экзоне, приводящая к образованию стоп-кодона, прерывающего трансляцию. В нульаллеле гена $L x 2$ единичная замена $T \rightarrow A$ в $L x 2$ заменяет гистидин Н532, один из железосвязывающих лигандов, важных для L-2 активности, на глутамин. Мутации в нуль-аллеле гена липоксигеназы 3 ( $L x 3)$ находятся в регионе промотора и представляют две единичные замены в АААТАС-боксе (Reinprecht et al., 2011). На основе известных мутаций могут быть созданы молекулярные маркеры пониженного содержания липоксигеназы.

\section{Caxapa}

Количество сахаров представляет одно из ценных качеств семян сои. Из водорастворимых сахаров в сое присутствует в основном дисахарид - сахароза - и трисахариды - стахиоза и раффиноза. Содержание сахарозы обычно составляет $4.0-4.5 \%$ от сухого вещества.

Сахароза - желательный компонент семени для вкуса и аромата. Раффиноза и стахиоза действуют как антипищевые факторы, затрудняющие переваривание (Akond et al., 2015). M. Akond с коллегами (2015) представили результаты картирования 14 главных QTL, связанных с содержанием сахаров. Tpи QTL для содержания сахарозы были картированы на хромосомах 3, 9 и 15; семь QTL для содержания рафинозы на хромосомах 1, 3, 6, 9, 14 и 16; четыре QTL для содержания стахиозы - на хромосомах 1, 6, 12 и 14. Выбор для выгодных аллелей этих QTLS может облегчить селекцию сои с более высокими концентрациями сахарозы и более низкими рафинозы и стахиозы.

\section{Фитиновая кислота}

Накопление фитиновой (инозитгексафосфорной) кислоты в семенах сои значительно ухудшает кормовые свойства, поэтому отбор растений с низким содержанием фитиновой кислоты является важной задачей. D.R. Walker и др. (2006) описали два локуса, связанные с низким содержанием фитиновой кислоты, между локусами было обнаружено эпистатическое взаимодействие. Один из локусов, pha1, был картирован на хромосоме 3 около Satt237, другой локус, pha2, был картирован на 19 хромосоме около Satt527.

\section{Ингибитор трипсина Кунитса}

Ингибитор трипсина (Soybean Kunitz trypsin inhibitor, SKTI) мономерный и негликозилированный белок, содержащий 181 аминокислотный остаток. Известно, что он снижает питательные свойства сырой сои и разрушается длительным нагреванием. В сое он кодируется десятью независимыми генами; из них KTI3 самый значимый, поскольку преимущественно экспрессируется в семенах. В настоящее время известно 13 изоформ белка КТІ3, которые кодируются един- 
ственным геном с несколькими аллелями (Qi et al., 2016). Последовательность ДНК рецессивного аллеля kti содержит одну замену и две делеции, которые влияют на трансляцию, снижая содержание KTI в эмбрионах семени. Установлено, что с аллелем kti связаны три SSR-маркера: Satt228, Satt409 и Satt429 (Maranna et al., 2016).

R.M. Alves de Moraes с коллегами (2006) создали праймеры для амплификации рецессивных аллелей, обуславливающих отсутствие лектина, который также снижает питательную ценность соевых бобов, и ингибитора трипсина Кунитса (см. табл. 2).

\section{Изофлавоны}

Изофлавоны полезны для здоровья человека, важно лишь ограничивать их количество в продуктах детского питания и питания беременных. В некоторых странах диетологами рекомендован безопасный верхний предел ежедневного потребления изофлавонов. Селекционеры ведут работы по выведению сортов сои с пониженным содержанием изофлавонов с целью рекомендации такой сои для производства детских молочных смесей.

Было картировано несколько QTL для трех разновидностей изофлавонов: генистеина (GEN), даидзеина (DAI), глицитеина (GLY), а также для общего количества изофлавонов (ТОТ) (Gutierrez-Gonzalez et al., 2010). J.J. Gutierrez-Gonzalez с сотрудниками идентифицировали и валидировали главный QTL на хромосоме 5, который значительно влияет на накопление как отдельных изофлавонов, так и на их общее накопление. Другой главный QTL на хромосоме 8 идентифицировали К. Yang с коллегами (2011).

Y. Wang с сотрудниками (Wang et al., 2015) идентифицировали 34 QTL, связанных с индивидуальными изофлавонами и общим содержанием изофлавонов, на 13 группах сцепления. Среди них 6 QTL связаны с DZ (daidzein - даидзеин), 7 - c GC (glycitein - глицитеин), 10 - с GT (genistein - генистеин) и 11 - с TI (total isoflavone - общий изофлавон). Три QTL (qDZF_2, qGTF_1, qTIF_2), связанные с DZ, GT и TI, расположены на хромосоме 13 между маркерами Satt144-Satt569. Еще три QTL, ассоциированные с GC, GT и TI, находятся на хромосоме 7 между маркерами Satt540-Sat_244 (Wang et al., 2015).

\section{Содержание токоферола}

Семейство витамина Е включает четыре формы токоферолов - $a, \beta, \gamma$ и $\delta$. Все изоформы предотвращают окисление липидов, но а-токоферол обладает наибольшей антиокислительной активностью у млекопитающих. Главные формы токоферолов в семенах сои, $ү$-токоферол и $\delta$-токоферол, составляют 60-70 и 20-25\% общего токоферола соответственно, тогда как содержание а-токоферола обычно менее $10 \%$. Витамин Е широко используют как антиоксидант в продуктах и маслах и как пищевую добавку для улучшения качества мяса у домашней птицы и коров. Добавляемый в рацион питания витамин Е помогает предотвращать онкологические и сердечно-сосудистые заболевания (Dwiyanti et al., 2011). В ранних исследованиях M.S. Dwiyanti c коллегами (2011) определили два SSR маркера, связанных с концентрацией а-токоферола, Sat_243 и Sat_167, на хро- мосоме 9. Позднее авторы подтвердили, что QTL в интервале Sat_243 и KSC138-17 положительно регулирует концентрацию а-токоферола, снижая при этом концентрацию ү-токоферола, что указывает на то, что ген-кандидат связан с преобразованием $\mathrm{\gamma}$-токоферола в а-токоферол. Этим исследователям удалось определить ген, содержащийся в QTL для высокого уровня а-токоферола; им оказался $\mathrm{\gamma}$-ТМТ3, кодирующий ү-токоферол метилтрансферазу.

\section{Селекция овощной сои}

Овощная соя (рис. 5), также названная 'mao dou' (означает 'волосатые бобы') в Китае, 'edamame' (означает 'бобы на ветках') в Японии, 'зеленая овощная соя' или'соя овощного типа' в Северной Америке, - это специализированные сорта сои, потребляемые в свежем виде или используемые для приготовления. В наше время овощная соя очень популярна как компонент здорового питания (Dong et al., 2014). Овощную сою собирают, как правило, когда стручки еще зеленые, а наполненность семян примерно 80-90\%. Большие зеленые стручки (длина более 4.5 см, ширина более $1.3 \mathrm{~cm}$ ), крупные семена (более 30 г/100 семян сухого веса), зеленая оболочка семян, высокое содержание сахаров, особенно сахарозы, гладкая текстура и лучший аромат, чем у зерновой сои, - это особенности овощной сои. Ее употребляют в виде свежих стручков на ветках, отдельных стручков, очищенных бобов, а также в замороженном и консервированном виде. Китай крупнейший производитель овощной сои в мире.

Овощные сорта сои "Dadachamame" и "Chakaori" характеризуются приятным ароматом из-за наличия летучего соединения 2-acetyl-1-pyrroline (2AP) (Arikit et al., 2011), которое найдено также в ароматном рисе. При помощи QTL-анализа был идентифицирован главный QTL аромата в сое на хромосоме 5, и он совпадает с положением гена бетаин альдегид дегидрогеназы 2 (betaine aldehyde dehydrogenase 2, $G m B A D H 2)$, тот же ген отвечает за аромат риса (см. табл. 2). При сравнении последовательностей GmBADH2 у сортов ароматной и неароматной сои обнаружена несинонимичная замена нуклеотида в экзоне 10, приводящая к замене глицина на аспарагиновую кислоту. Пять аллель-специфичных SNP-маркеров было разработано R. Juwattanasomran с коллегами (2011). Еще один маркер был создан ими же в 2012 г. на базе (ТT)-делеции в 10-м экзоне GmBADH2. Все маркеры, разработанные к аллельным вариантам гена GmBADH2, можно применять в маркер-опосредованной селекции (см. табл. 2).

\section{Устойчивость к болезням,} вредителям и нематодам

Способность растений сои противостоять болезням и вредителям очень важна для получения хорошего урожая. В последние десятилетия молекулярные маркеры активно используются для отбора резистентных растений.

\section{Нематоды}

Клубеньковые нематоды, наряду с цистообразующими нематодами, вызывают серьезные потери урожая в областях с теплым климатом и песчаными почвами. М. Хu с сотрудниками (2013) идентифицировали два гена-кандидата, лежа- 


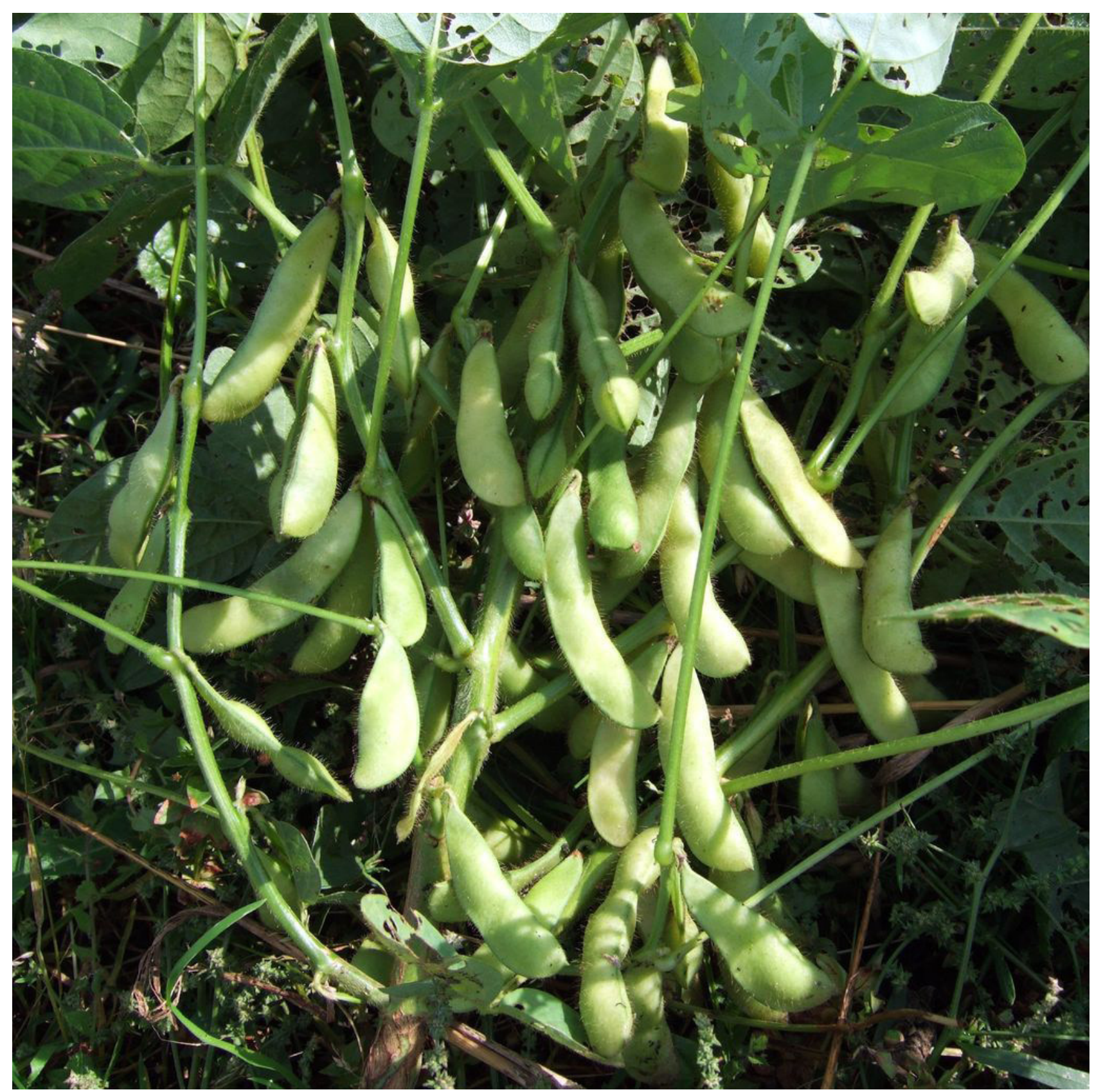

Рис. 5. Овощная соя. Источник: https://pomidom.ru/edamame/\#\&gid=1\&pid=1

щих в главных QTL устойчивости к клубеньковой нематоде на хромосоме 10. Это ген Glyma10g02150, кодирующий ингибитор пектин метилэстеразы, и Glyma10g02160, кодирующий пектиновую метилэстеразу.

Соевая цистообразующая нематода (СЦН). Устойчивость к СЦН наследуется комплексно (Tran et al., 2019). Более $30 \mathrm{QTL}$, контролирующих резистентность к СЦН, были найдены с 1994 г., но большинство из них имело незначительный эффект. Было обнаружено только два главных QTL: Rhg1 (Resistance to H. glycines 1) на хромосоме 18 и Rhg4 на хромосоме 8. В локусе Rhg1 идентифицированы три гена: Glyma.18g02580, Glyma.18g02590 и Glyma.18g02610. Ген Glyma.18g02580 кодирует предположительно аминокислотный транспортер; ген Glyma.18g0290 - белок а-SNAP, а ген
Glyma.18g02610 кодирует индуцируемый повреждением белок 12(WI 12). Локус Rhg4 содержит ген, кодирующий серингидроксиметилтранферазу (SHMT) (см. табл. 2).

D.T. Tran c коллегами (2019) выявили новые главные QTL, связанные с устойчивостью к СЦН, на хромосомах 7 и 10. Какие гены, находящиеся в этих локусах, задействованы в механизмах устойчивости, еще предстоит выяснить.

\section{Бактериальные заболевания}

Пустульный бактериоз вызывается патогеном Xanthomonas axonopodis pv. glycines. Основной локус устойчивости к этому заболеванию был изначально картирован на хромосоме 17 между SSR-маркерами Satt486 и Satt372 (Chang et al., 2016). Позднее при более точном картировании был лока- 
лизован в районе 33 kb между SNP-маркерами SNUSSR17_9 и SNUSNP17_2\&_12, где были найдены два гена-кандидата. Были также обнаружены минорные QTL на хромосомах 4, 5, 10, 13, 17, и 19 (Chang et al., 2016).

Грибные заболевания

Коричневая стволовая гниль вызывается почвенным грибом Cadophora gregata. Главные локусы резистентности были найдены на хромосоме 16 . Сюда входят локусы Rbs 1 от линии сои L78-4094 (Hanson et al., 1988), Rbs2 от PI 437833 (Hanson et al., 1988), и Rbs3 от PI 437970 и 'BSR101 (Willmot, Nickell, 1989). Rbs1 и Rbs2 были позже картированы между SSR-маркерами Satt215 к Satt431 и Satt244 к Satt431 соответственно.

K. Rincker с сотрудниками (2016) картировали локусы устойчивости к коричневой стволовой гнили более точно и обнаружили, что все три локуса умещаются в интервале от маркера BARCSOYSSR_16_1114 до BARCSOYSSR_16_1115 и, похоже, составляют один локус. В этом локусе обнаружены гены резистентности Glyma.16g169600, Glyma.16g169700 и Glyma.16g169900.

Диапортоз, или фомопсис сои вызывается грибами Diaporthe phaseolorum var. caulivora и $D$. phaseolorum var. meridionalis. В разных сортах сои были идентифицированы 4 доминантных неаллельных локуса, обуславливающих резистентность к D. phaseolorum var. Caulivora: это Rdc1 и Rdc2 в 'Tracy M', Rdc3 в 'Crockett', и Rdc4 в 'Dowling' и 'Hutcheson' (Chang et al., 2016). В 2003 г. было показано, что сорта с локусами с $R d c 1$ по Rdc4 показывают устойчивость к $D$. phaseolorum var. Meridionalis, но не к $D$. phaseolorum var. caulivora, поэтому локусы были переименованы соответственно в $R d m 1-R d m 4$. Позднее был выявлен локус $R d m 5$ в сорте 'Hutcheson'. В 2017 г. было сообщено о картировании локусов Rdm4 и Rdm5 на хромосоме 8, установлено, что SSRмаркеры Sat_162 и Satt233 фланкируют локусы Rdm4 и Rdm5 (Chiesa et al., 2017).

Фитофтороз вызывается грибом Phytophthora sojae. Обнаружено 19 локусов, связанных с устойчивостью к фитофторозу. Сюда входят Rps1 (шесть аллелей), Rps7, Rps9, RpsYu25 и RpsYD29 на хромосоме 3, Rps2 и RpsUN2 на хромосоме 16; Rps3 (три аллели) и Rps8 на хромосоме 13; Rps4, Rps5, Rps6 и RpsJS на хромосоме 18. У большинства коммерческих культурных сортов имеется резистентность к этому заболеванию. Чаще всего в последнее десятилетие для селекции использовали аллели Rps1k, Rps1a и Rps1c. J. Ping с коллегами (2015) описали новый ген, связанный с резистентностью к Phytophthora sojae. Ген был обнаружен на хромосоме 7, где ранее не было картировано ни одного Rps-локуса, и назван Rps 11. Ген Rps 11 расположен между SSR-маркерами BARCSOYSSR_07_0286 и BARCSOYSSR_07_0300.

D.K. Sahoo с сотрудниками (2017) идентифицировали еще один ген устойчивости к Phytophthora sojae - Rps12. Ген картирован между маркерами BARCSOYSSR_18_1840 и Sat_064 SSR, расположенными на хромосоме 18. В 2019 г. на хромосоме 3 был обнаружен гена резистентности $R p s X$, который был нанесен на карту между InDel-маркером InDelxz6 и SSR маркером BARCSOYSSR_03_0175, ген также связан с тремя SSRмаркерами (BARCSOYSSR_03_0161, BARCSOYSSR_03_0165 и BARCSOYSSR_03_0167) (Zhong et al., 2019).
Механизмы резистентности пока недостаточно исследованы, ведется активная работа по их изучению. Поскольку патоген активно изменяется и приспосабливается, необходим постоянный поиск новых генов резистентности (Zhang et al., 2019).

Синдром внезапной смерти (SDS) сои вызывается почвенным грибом Fusarium virguliforme. В сое SDS-резистентность к нему кодируется мультигенно и имеет два компонента: листовая устойчивость к грибным токсинам и частичная устойчивость к внедрению гриба в корень. В настоящее время описано более 80 QTL, связанных с SDSрезистентностью. К сожалению, валидация этих QTL под вопросом из-за изменчивости, обусловленной взаимодействием генотипов сои с окружающей средой, синергизма SDS с цистообразующей нематодой, отсутствия единой номенклатуры QTL и т. п. (Chang et al., 2018).

Локус Rfs2/Rhg1 на хромосоме 18 обеспечивает частичную устойчивость к инфицированию корня патогеном F. virguliforme и резистентность к цистообразующей нематоде. Локус Rfs2/Rhg1 кодирует рецепторо-подобную киназу (GmRLK18-1), ответственную за устойчивость к SDS и SCN.

S. Swaminathan с коллегами (2019) сообщили о нахождении новых SNP-маркеров, ответственных как за листовую, так и за корневую устойчивость к SDS. Авторы идентифицировали гены устойчивости, связанные с найденными маркерами. Из трех генов, ассоциированных с листовой устойчивостью, два кодируют LRR-рецепторы (Leucine-rich repeat - LRR), и третий кодирует новый белок с неизвестной функцией. Из двух генов корневой устойчивости ген Glyma.01g222900.1 кодирует специфичный для сои белок LEA, а ген Glyma.10g058700.1 - гепаран-альфа-глюкозаминид $\mathrm{N}$-ацетилтрансферазу.

Ржавчина сои вызывается Phakopsora pachyrhizi. Обычные симптомы - поражения листа от светло- до темно- или красновато-коричневого цвета, с одной или множественными пылящими шаровидными урединиями. Локус устойчивости Rpp1 картирован на хромосоме 18, локус Rpp2 - на хромосоме 16, а локус Rpp3 - на хромосоме 6, Rpp4 - на хромосоме 18, Rpp5 - на хромосоме 3, Rpp6 - на хромосоме 18. Показано, что локус Rpp2 тесно связан с маркерами Satt215, Sat_361 и Satt621, а локус Rpp4, картированный между маркерами Satt288 и AF162283, - с маркерами Sat_143 и Satt612 (Silva et al., 2008). Локус Rpp3 был исследован, и маркер Satt460, сцепленный с локусом, рекомендован для использования при проведении MOC (Okii et al., 2014).

Церкоспороз вызывается грибом Cercospora sojina Hara. Церкоспороз сои может снижать урожайность культуры в 3-8 раз, уменьшая качество семян и посевные свойства. Ген $R c s 3$ кодирует устойчивость ко всем известным расам возбудителя. Ген Rcs3 картирован возле микросателлита Satt244 на расстоянии 0.50 сM от однуклеотидных маркеров (SNPs) AZ573TA150 и AZ573CA393 (Zhang et al., 2019).

Вирусные заболевания

Вирус мозаики сои (Soybean mosaic virus - SMV) - распространенный патоген сои, выявленный во многих ареалах ее выращивания. Геном SMV - одноцепочечная (+)PHK, с которой может транслироваться 11 белков. Как известно, в рас- 
тениях многие гены резистентности (R) вовлечены в активацию врожденного иммунного ответа. Большинство R-белков имеет нуклеотид-связывающий сайт и регион обогащенных лейцином повторов (NBS-LRR). У некоторых R-белков типа NBS-LRR двудольных растений имеется TIR-мотив (Toll/Interleukin-1 Receptor). К сожалению, роль R-белков сои в формировании резистентности изучена слабо. Ранее были идентифицированы три R-локуса устойчивости к SMV Rsv1, Rsv3 и Rsv4 (Saghai Maroof et al., 2008). Известны и SSR-маркеры для отбора необходимых аллелей генов: Rsv1 маркируется Sat_154 и Satt510, а также специфическим маркером Rsv1$f / r$, ген Rsv3 - двумя микросателлитными маркерами Satt560 и Satt063; а аллель Rsv4 - микросателлитом Satt266 и ESTsмаркерами Al856415, Al856415-g (Shi et al., 2009). Но, как оказалось, каждый из этих генов демонстрирует резистентность только к некоторым штаммам SMV. Ген устойчивости к BCMV (Bean common mosaic virus) был картирован между маркерами 13_1114 и SNP-49 почти в том же самом месте, что и ген Rsv1- $h$ устойчивости к SMV; это позволило авторам работы предположить, что за устойчивость к обоим вирусам отвечает один и тот же ген (Wu et al., 2018).

Недавно стали известны сведения о влиянии сверхэкспрессии гена GmKR3 (Glycine max Kefeng1 resistance gene 3) на устойчивость к SMV (Xun et al., 2019). Сверхэкспрессия этого гена увеличивала устойчивость к потивирусам, таким как вирус обыкновенной мозаики фасоли BCMV, вируса мозаики арбуза WMV, вируса пятнистости стручков фасоли BPMV. При этом не отмечено влияния сверхэкспрессии гена GmKR3 на развитие и урожайность растений, но возрастало содержание абсцизовой кислоты. Предполагают, что сверхэкспрессия $G m K R 3$ увеличила вирусную устойчивость сои при помощи активации сигнальных путей, связанных с абсцизовой кислотой. Интересно, что из всех известных в настоящее время QTL, связанных с устойчивостью к SMV, ни один не картирован на хромосоме 6, где расположен ген GmKR3.

В последних исследованиях также показано, что сверхэкспрессия гена PAC $_{1}$ (РНКаза из семейства РНКаз III, расщепляющих двуцепочечную РНК) увеличивает резистентность к заражающим сою вирусам, включая SMV, BCMV, WMV и BPMV. В процессе вирусной репликации одноцепочечные вирусные РНК могут создавать двуцепочечные структуры, которые расщепляются белком PAC1 (Yang et al., 2019).

\section{Устойчивость к абиотическому стрессу}

Для получения высоких урожаев сои, несомненно, необходимы исследования взаимодействия генотипа и абиотических факторов среды, например таких, как засуха, низкие температуры и другие. На хромосоме 8 картирован QTL морозоустойчивости сои, он расположен рядом с SSR-маркером Sat_162 (Ikeda et al., 2009). Выращивание сои при низких температурах на стадии цветения вызывает появление коричневой окраски рубчика семян, что снижает рыночную стоимость бобов. Обнаружено 5 QTL пигментации рубчика, которые были обозначены с pig1 по pig5 и картированы на хромосомах 8, 11, 6, 16 и 3 соответственно. Локус pig3 локализован рядом с геном E1 фотопериодизма (Githiri et al., 2007). Обнаружено также пять QTL-локусов устойчивости сои к алюминию (Qi et al., 2008).
Идентификация генов, отвечающих за архитектуру корневой системы, очень важна для селекции засухоустойчивой сои. S.J. Prince с сотрудниками (2015) обнаружили 4 главных QTL, ассоциированных с архитектурой корня, на хромосомах 6 и 7. Найден ряд генов-кандидатов для архитектуры корня, из них наиболее интересны ген триглицерид липазы (triglyceride lipase), два гена, кодирующих ингибиторы апоптозиса (арорtosis inhibitory 5 family protein), ген оксидоредуктазы/белка, связывающего ионы переходных металлов (охidoreductase /transition metal ion binding protein), ген циклина типа D6 и ген выходного канала ауксина (hormone auxin-associated gene auxin efflux carrier protein gene). L.P. Manavalan с коллегами (2015) обнаружили на хромосоме 8 главный QTL, который был связан с архитектурой корня, и идентифицировали шесть факторов транскрипции и два гена ксилоглюканэндотрансгликозилаз в качестве генов-кандидатов в найденном QTL. K настоящему времени обнаружено несколько QTL, ассоциированных с архитектурой корня, но влияние этих QTL на устойчивость к засухе еще до конца не выяснено (Valliyodan et al., 2017).

Главный QTL, связанный с солеустойчивостью, был картирован на хромосоме 3. В этом QTL определен ген Glyma03g32900 со вставкой ретротранспозона типа Ту1/ copia. G. Patil с сотрудниками (2016) разработали молекулярный маркер для солеустойчивости (см. табл. 2).

\section{Фиксация азота}

Биологическая фиксация азота - процесс, представляющий большой интерес, но, к сожалению, исследования QTL, контролирующих этот процесс, малочисленны (Santos et al., 2013). M.A. Santos с коллегами в 2013 г. выявили нескольких QTL, ассоциированных с количеством узелков (NN), отношением сухого веса узелков к их количеству (NDW/NN) и с сухим весом побега (SDW). Локус nn1-B1(NN, NDW/NN) был картирован на хромосоме 11 в интервале Satt509-Satt251 и связан с метоболизмом изофлавонов; локус $s d w 2-L$ находился на хромосоме 19 в интервале Satt232-Satt418 (связан c SDW, NN, NDW/NN), примерно в той же области, как известно, находятся локусы, контролирующие высоту растения; локус bnf3-E был найден на хромосоме 15 в интервале Satt573-Satt185 (связан с SDW и NN); локус bnf4-I (связан с NN и NDW/NN) находился на хромосоме 20 в интервале Satt587-Satt354 и совпадал с QTL содержания белка (Santos et al., 2013).

K 2019 г. было идентифицировано 18 QTL, ассоциированных с биологической фиксацией азота, распределение их по хромосомам выглядит так: 2 на 1-й хромосоме, 1 на 4-й хромосоме, 1 на 5-й, 4 на 6-й, 1 на 8-й, 1 на 9-й, 1 на 11-й, 2 на 15-й, 2 на 19-й и 3 на 20-й (Yang et al., 2019). Q. Yang с сотрудниками (2019) представили результаты изучения двух новых QTL, qBNF-16 на хромосоме 16 и qBNF-17 на хромосоме 17, ассоциированных с фиксацией азота.

\section{Генетические карты сои}

Р. Keim с коллегами (1990) опубликовали первую генетическую карту сои с использованием молекулярных маркеров. Поскольку частота полиморфных RFLP маркеров в сое низкая, карта была получена через межвидовую помесь ком- 
мерческого культурного сорта (А81-356022) и линии сои вида Glycine soja (PI 468916). На карту были нанесены 150 маркеров RFLP и 3 классических локуса. Позже ее дополняли другие исследователи (Lopes da Silva et al., 2017).

В 1995 г. была получена первая генетическая карта сои с микросателлитными маркерами (Akkaya et al., 1995). Она coдержала 40 микросателлитных маркеров, а также 118 RFLP и RAPD-маркеров, 13 классических маркеров, контролирующих пигментацию и морфологические характеристики, и 7 изоферментов.

Карту с использованием SSR-маркеров (всего 606) получили в 1999 г. Р.B. Creagan соавторами. Карта содержала также 689 RFLP, 79 RAPD, 11 AFLP, 10 изоферментных маркеров и 26 классических локусов. Хотя это была не первая генетическая карта сои, в этой работе впервые 20 консенсусных групп сцепления соответствовали 20 хромосомам сои. Таким образом, исследователям удалось разработать микросателлитные маркеры для всех 20 хромосом сои (Creagan et al., 1999).

Q.J. Song с сотрудниками (2004) обновили консенсусную карту, включив в нее 420 новых маркеров. В результате консенсусная карта содержала 1837 маркеров, из которых 1015 были микросателлитными, 709 RFLPs, 73 RAPDs, 24 классических маркера, 6 AFLPs и 10 изоферментов (Song et al., 2004).

І.-Y. Choi с коллегами (2007) включили в консенсусную карту SNP-маркеры. К 2017 г. в нее были добавлены 1059 SNP, полученных из 1141 различного гена, расположенного на 20 хромосомах (Yang Q. et al., 2019).

В 1999 г., а затем в 2003 г. группа исследователей из Министерства сельского хозяйства США получила интегрированную генетическую карту, которая объединяла данные нескольких популяций. Поскольку эта карта содержала все генетические маркеры, стало возможно поместить все опубликованные QTL в одну карту вместе с различными типами маркеров, необходимыми для их описания. Эта карта находится в SoyBase, под названием GmComposite2003, и базируется на карте, изначально полученной Q.J. Song c coавторами (2004).

В последнее время количество молекулярных маркеров стало расти слишком быстро за счет новых SNP-маркеров. В связи с чем в настоящий момент существуют две генетических карты: GmComposite2003, на которую постоянно добавляют новые QTL, и консенсусная карта (в настоящее время в 4-й версии), которая называется GmConsensus4.0 и содержит SNP-маркеры и микросателлиты, находящиеся в геномной последовательности образца "Williams 82" (Wm82).

В 2017 г. генетическая карта GmComposite2003 состоит из 3245 маркеров, 89 генов и 3027 картированных QTLs. На карте GmConsensus4.0 нет QTL и генов, но благодаря возможности выравнивания карт можно соотносить между собой молекулярные маркеры, QTL и гены (Lopes da Silva et al., 2017). Таким образом, в настоящее время есть все предпосылки для более интенсивного вовлечения молекулярных маркеров в селекцию сои.

\section{Список литературы/References}

Абугалиева С.И. Генетическое разнообразие сои (Glycine max (L.) Merill). Биотехнология. Теория и практика. 2013;4:13-19.

[Abugalieva S.I. Genetic diversity of Soybean (Glycine max (L.) Merrill). Biotechnology. Theory Practice. 2013;4:13-19. (in Russian)]
Вавилов Н.И. Центры происхождения культурных растений. Тр. по прикл. ботанике, генетике и селекции. 1926;16(2):248.

[Vavilov N.I. Centres of origin of cultivated plants. Tr. po prikl. botan. selektsii. 1926;16(2):248. (in Russian)]

Вишнякова М.А., Сеферова И.В., Самсонова М.Г. Требования к исходному материалу для селекции сои в контексте современных биотехнологий. Сельскохоз. биология. 2017;52(5):905-916.

[Vishnyakova M.A., Seferova I.V., Samsonova M.G. Genetic sources required for soybean breeding in the context of new biotechnologies. Agrobiol. 2017;52 (5):905-916. (in Russian)]

Енкен В.Б. Соя. М.: Гос. изд-во с.-х. лит-ры, 1959.

[Enken V.B. Soya. Moscow: Gos. izd-vo s.-kh. lit-ry, 1959. (in Russian)]

Жуковский П.М. Культурные растения и их сородичи. Л.: Колос, 1964. [Zhukovsky P.M. Cultured plants and their relatives. Leningrad: Kolos; 1964. (in Russian)]

Киселёва А.А., Салина Е.А. Генетические механизмы формирования времени колошения мягкой пшеницы. Генетика. 2018;54(4):381396.

[Kiseleva A.A., Salina E.A. Genetic regulation of common wheat heading time. Russian J. Genetics. 2018;54(4):375-388.]

Салина Е.А. Технологии геномного моделирования и редактирования для решения задач селекции растений. Достижения науки и техники АПК. 2016;9:9-14.

[Salina E.A. Genome modeling and editing technologies for solving the breeding challenges. Achievements Sci. Technol. AIC. 2016;9:9-14. (in Russian)]

Akkaya M.S., Shoemaker R.C., Specht J.E., Bhagwat A.A., Cregan P.B. Integration of simple sequence repeat DNA marker into a soybean linkage map. Crop Sci. 1995;35:1439-1445.

Akond M., Liu S., Boney M., Kantartzi S. K., Meksem K., Bellaloui N., Lightfoot D.A., Kassem M.A. Identification of quantitative trait loci (QTL) underlying protein, oil, and five major fatty acids' contents in soybean. Am J Plant Sci. 2014;5(1):158-167.

Akond M., Liu S.M., Kantartzi S.K., Meksem K., Bellaloui N., Lightfoot D.A., Kassem M.A. Quantitative trait loci underlying seed sugars content in "MD96-5722" by "Spencer" recombinant inbred line population of soybean. Food Nutr Sci. 2015;6:964-973.

Alves de Moraes R.M., Soares T.C.B., Colombo L.R., Salla M.F.S., Barros J.G. de A., Piovesan N.D., Barros E.G., de Moreira M.A. Assisted selection by specific DNA markers for genetic elimination of the kunitz trypsin inhibitor and lectin in soybean seeds. Euphytica. 2006;149 (1-2):221226. doi: 10.1007/s10681-005-9069-0.

Arikit S., Yoshihashi T., Wanchana S., Tanya P., Juwattanasomran R., Srinives P., Vanavichit A. A PCR-based marker for a locus conferring aroma in vegetable soybean (Glycine max L.). Theor Appl Genet. 2011;122: 311-316.

Arumuganathan K., Earle E.D. Nuclear DNA content of some important plant species. Plant Mol Biol Rep. 1991;9:208-218.

Bachlava E., Dewey R.E., Auclair J., Wang S., Burton J.W., Cardinal A.J. Mapping genes encoding microsomal $\omega-6$ desaturase enzymes and their cosegregation with QTL affecting oleate content in soybean. Crop Sci. 2008;48(2):640-650.

Bellaloui N., Reddy K.N., Bruns A., Gillen A. M., Mengistu A., Zobiole L.H.S., Fisher D.K., Abbas H.K., Zablotowicz R., Kremer R.J. Soybean seed composition and quality: interactions of environment, genotype, and management practices. In: Soybeans: cultivation, uses and nutrition. J. Maxwell (ed.). Nova Sci Publ. 2011:1-42.

Chang H.-X., Lipka A.E., Domier L.L., Hartman G.L. Characterization of disease resistance loci in the USDA soybean germplasm collection using genome-wide association studies. Phytopathol. 2016;106(10): 1139-1151.

Chang H.-X., Roth M.G., Wang D., Cianzio S.R., Lightfoot D.A., Hartman G.L., Chilvers M.I. Integration of sudden death syndrome resistance loci in the soybean genome. Theor Appl Genet. 2018;131(4): pp 757-773.

Chapman A., Pantalone V.R., Ustun A., Allen F.L., Landau-Ellis D., Trigiano R.N., Gresshoff P.M. Quantitative trait loci for agronomic and seed quality traits in an F2 and F4:6 soybean population. Euphytica. 2003;129:387-393.

Chiesa M.A., Cambursano M.V., Pioli R.N., Morandi E. Molecular mapping of the genomic region conferring resistance to soybean stem canker in Hutcheson soybean. Mol Breed. 2017;37:65. doi: 10.1007/s11032017-0660-6. 
Choi I.-Y., Hyten D.L., Matukumalli L.K., Song Q.-J., Chaky J.M., Quig ley C.V., Chase K., Lark K.G., Reiter R.S., Yoon M.-S., Hwang E.-Y., Yi S.-I., Young N.D., Shoemaker R.C., van Tassel C.P., Specht J.E., Cregam P.B. A soybean transcript map: gene distribution, haplotype and SNP analysis. Genetics. 2007;176(1):685-696.

Creagan P.B., Jarvik T., Bush A.L., Shoemaker R.C., Lark K.G., Kahler A.L., Kaya N., van Toai T.T., Lohnes D.G., Chung J. An integrated genetic linkage map of the soybean genome. Crop Sci. 1999;39:1464-1490.

Csanádi G., Vollman J., Stift G., Lelly T. Seed quality QTLs identified in a molecular map of early maturing soybean. Theor Appl Genet. 2001; 103:912-919. doi: 10.1007/s001220100621.

de Montaigu A., Giakountis A., Rubin M., Tóth R., Cremer F., Sokolova V., Porri A., Reymond M., Weinig C., Coupland G. Natural diversity in daily rhythms of gene expression contributes to phenotypic variation. Proc Natl Acad Sci USA. 2015;112:905-910.

Dierking E., Bilyeu K.D. New sources of soybean seed meal and oi composition traits identified through TILLING. BMC Plant Biol. 2009; 9:89.

Dong D., Fu X., Yuan F., Chen, P., Zhu S., Li B., Yang Q., Yu X., Zhu D. Genetic diversity and population structure of vegetable soybean (Glycine $\max (\mathrm{L}$.) Merr.) in China as revealed by SSR markers. Genet Resour Crop Evol. 2014;61. doi: 10.1007/s10722-013-0024-y.

Dwiyanti MS., Yamada T., Sato M., Abe J., Kitamura K. Genetic variation of $\gamma$-tocopherol methyltransferase gene contributes to elevated a-tocopherol content in soybean seeds. BMC Plant Biol. 2011;11:152. doi: 10.1186/1471-2229-11-152.

Fang C., Ma Y., Wu S., Liu Z., Wang Z., Yang R., Hu G., Zhou Z., Yu H., Zhang M., Pan Y., Zhou G., Ren H., Du W., Yan H., Wan g Y., Han D., Shen Y., Liu S., Liu T., Zhang J., Qin H., Yuan J., Yuan X., Kong F., Liu B., Li J., Zhang Z., Wang G., Zhu B., Tian Z. Genome-wide association studies dissect the genetic networks underlying agronomical traits in soybean. Genome Biol. 2017;18:161. doi: 10.1186/s13059-0171289-9.

Funatsuki H., Suzuki M., Hirose A., Inaba H., Yamada T., Hajika M., Komatsu K., Katayama T., Sayama T., Ishimoto M., Fujino K. Molecular basis of a shattering resistance boosting global dissemination of soybean. Proc Natl Acad Sci U.S.A. 2014;111:17797-17802.

Githiri S.M., Yang D., Khan N.A., Xu D., Komatsuda T., Takahashi R. QTL analysis of low temperature induced browning in soybean seed coats. J Hered. 2007;98(4):360-366. doi: 10.1093/jhered/esm042.

Grant D., Nelson R.T., Cannon S.B., Shoemaker R.C. SoyBase, the USDAARS soybean genetics and genomics database. Nucleic Acids Res. 2010;38(suppl 1):D843-D846. doi: 10.1093/nar/gkp798.

Gutierrez-Gonzalez J.J., Wu X., Gillman J.D., Lee J.D., Zhong R., Yu O., Shannon G., Ellersieck M., Nguyen H.T., Sleper D.A. Intricate environment-modulated genetic networks control isoflavone accumulation in soybean seeds. BMC Plant Biol. 2010;10:105. doi: 10.1186/14712229-10-105.

Han Y., Li D., Zhu D., Li H., Li X., Teng W., Li W. QTL analysis of soybean seed weight across multi-genetic backgrounds and environments. Theor Appl Genet. 2012;125 (4):671-683.

Hanson P.M., Nickell C.D., Gray L.E., Sebastian S.A. Identification of two dominant genes conditioning brown stem rot resistance in soybean. Crop Sci. 1988;28:41-43. doi: 10.2135/cropsci1988.0011183X002800 010010x.

Hosamani J., Kumar M.B., Talukdar A., Lal S.K., Dadlani M. Molecular characterization and identification of candidate markers for seed longevity in soybean [Glycine max (L.) Merill]. Indian J Genet Plant Breed 2013;73(1):64-71. doi: 10.5958/j.0019-5200.73.1.009.

Hymowitz T. On the domestication of the soybean. Econ Bot. 1970; 24(4):408-421.

Hyten D.L., Pantalone V.R., Sams C.E., Saxton A.M., Landau-Ellis D., Stefaniak T.R., Schmidt M.E. Seed quality QTL in a prominent soybean population. Theor Appl Genet. 2004;109(3):552-561.

Ikeda T., Ohnishi S., Senda M., Miyoshi T., Ishimoto M., Kitamura K., Funatsuki $\mathrm{H}$. A novel major quantitative trait locus controlling seed development at low temperature in soybean (Glycine max). Theor Appl Genet. 2009;118(8):1477-1488. doi: 10.1007/s00122-009-0996-3.

Jeon N., Suh S.J., Kim M-H., Lee S., Moon J-K., Kim H.S., Jeong S-C., Jeon N., Suh S.J., Kim M-H., Lee S., Moon J-K., Kim H.S., Jeong S-C. $\mathrm{Ln}$ is a key regulator of leaflet shape and number of seeds per pod in soybean. Plant Cell. 2012;24:4807-4818.
Jiang B., Zhang S., Song W., Khan M.A.A., Sun S., Zhang C., Wu T., Wu C., Han T. Natural variations of FT family genes in soybean varieties covering a wide range of maturity groups. BMC Genet. 2019;20:230.

Juwattanasomran R., Somta P., Chankaew S., Shimizu T., Wongpornchai S., Kaga A., Srinives P. A SNP in GmBADH2 gene associates with fragrance in vegetable soybean variety "Kaori" and SNAP marker development for the fragrance. Theor Appl Genet. 2011;122:533-541. doi: 10.1007/s00122-010-1467-6.

Juwattanasomran R., Somta P., Kaga A., Chankaew S., Shimizu T., Sorajjapinun W., Srinives $P$. Identification of a new fragrance allele in soybean and development of its functional marker. Mol. Breed. 2012;29: 13-21. doi: 10.1007/s11032-010-9523-0.

Kadam S., Vuong T.D., Qiu D., Meinhardt C.G., Song L., Deshmukh R., Patil G., Wan J., Valliyodan B., Scaboo A.M., Shannon J.G., Nguyen H.T. Genomic-assisted phylogenetic analysis and marker development for next generation soybean cyst nematode resistance breeding. Plant Sci. 2016;242:342-350. doi: 10.1016/j.plantsci.2015.08.015.

Kato S., Sayama T., Fujii K., Yumoto S., Hwang Y. K.T-Y., Kikuchi A., Takada Y., Tanaka Y., Shiraiwa T., Ishimoto M. A major and stable QTL associated with seed weight in soybean across multiple environments and genetic backgrounds. Theor Appl Genet. 2014;127(6):13651374

Keim P., Diers B.W., Olson T.C., Shoemaker R.C. RFLP mapping in soybean: aasociation between marker loci and variation in quantitative traits. Genetics. 1990;126:735-742 2.

Kim M., Schultz S., Nelson R.L., Diers B.W. Identification and fine mapping of a soybean seed protein QTL from PI 407788A on chromosome 15. Crop Sci. 2016;56(1):219-225.

Kumawat G., Gupta S., Ratnaparkhe M.B., Maranna S., Satpute G.K. QTLomics in soybean: a way forward for translational genomics and breeding. Front Plant Sci. 2016;7:1852.

Lin J.-Y., Stupar R.M., Hans C., Hyten D.L., Jackson S.A. Structural and functional divergence of a 1-Mb duplicated region in the Soybean (Glycine max) genome and comparison to an orthologous region from Phaseolus vulgaris WOA. Plant Cell. 2010;22:2545-2561.

Liu B., Kanazawa A., Matsumura H., Takahashi R., Harada K., Abe J. Genetic redundancy in soybean photoresponses associated with duplication of phytochrome A gene. Genetics. 2008;180:996-1007. doi: 10.1534/genetics.108.092742.

Liu D., Yan Y., Fujita Y., Xu D. Identification and validation of QTLs for 100-seed weight using chromosome segment substitution lines in soybean. Breed Sci. 2018;68:442-448.

Lopes da Silva F., Borém A., Sediyama T., Ludke W.H. Soybean genetic mapping. In: Soybean breeding. Springer International Publishing AG, 2017. doi: 10.1007/978-3-319-57433-2.

Lu S., Zhao X., Hu Y., Liu S., Nan H., Li X., Fang C., Cao D., Shi X., Kong L., Su T., Zhang F., Li S., Wang Z., Yuan X., Cober E.R., Weller J.L., Liu B., Hou X., Tian Z., Kong F. Natural variation at the soybean J locus improves adaptation to the tropics and enhances yield. Nat Genet. 2017;49:773-779.

Lu X., Xiong Q., Cheng T., Li Q.-T., Liu X.-L., Bi Y.-D., Li W., Zhang W.-K., Ma B., Lai Y.-C., Du W.-G., Man W.-Q., Chen S.-Y., Zhang J.-S. A PP2C-1 allele underlying a quantitative trait locus enhances soybean 100-seed weight. Mol Plant. 2017;10:670-684.

Ma Y., Kan G., Zhang X., Wang Y., Zhang W., Du H., Yu D. QTL mapping for glycinin and $\beta$-conglycinin contents in soybean (Glycine max L. Merr.) J Agric Food Chem. 2016;64(17).

Manavalan L.P., Prince S.J., Musket T.A., Chaky J., Deshmukh R., Vuong T.D., Song L., Cregan P.B., Nelson J.C., Shannon J.G., Specht J.E., Nguyen H.T. Identification of novel QTL governing root architectural traits in an interspecific soybean population. PLoS One. 2015;10(3): e0120490. doi: 10.1371/journal.pone.0120490.

Maranna S., Verma K., Talukdar A., Lal S.K., Kumar A. Mukherjee K. Introgression of null allele of Kunitz trypsin inhibitor through markerassisted backcross breeding in soybean (Glycine max L. Merr.). BMC Genet. 2016;17:106.

Monteros M.J., Burton J.W., Boerma H.R. Molecular mapping and confirmation of QTLs associated with oleic acid content in N00-3350 soybean. Crop Sci. 2008;48:2223-2234.

Nakamura T., Yang D., Kalaiselvi S., Uematsu Y., Takahashi R. Genetic analysis of net like cracking in soybean seed coats. Euphytica. 2003; 133:179-184. 
Nico M., Mantese A.I., Miralles D.J., Kantolic A.G. Soybean fruit development and set at the node level under combined photoperiod and radiation conditions. J Exp Bot. 2016;67:365-377.

Okii D., Chilagane L.A., Tukamuhabwa P., Maphosa M. Application of bioinformatics in crop improvement: annotating the putative soybean rust resistance gene Rpp3 for enhancing marker assisted selection. J Proteom Bioinform. 2014;7:001-009. doi: 10.4172/jpb.1000296.

Owen F.V. Inheritance studies in soybean. II. Glabrousness, color of pubescence, time of maturity, and linkage relations. Genetics. 1927;12 519-529.

Pandurangan S., Pajak A., Molnar S.J., Cober E.R., Dhaubhadel S., Hernández-Sebastià C., Kaiser W.M., Nelson R.L., Huber S.C., Marsolais F. Relationship between asparagine metabolism and protein concentration in soybean seed. J Exp Bot. 2012;63(8):3173-3184. doi: 10.1093/jxb/ers039.

Panthee D.R., Pantalone V.R., Sams C.E., Saxton A.M., West D.R., Orf J.H., Killam A.S. Quantitative trait loci controlling sulfur containing amino acids methionine and cysteine, in soybean seeds. Theor Appl Genet. 2006;112:546-553.

Panthee D.R., Pantalone V.R., Saxton A.M., West D.R., Sams C.E. Genomic regions associated with amino acid composition in soybean. $\mathrm{Mol}$ Breed. 2006(a);17:79-89.

Patil G., Do T., Vuong T.D., Valliyodan, B., Lee J.D., Chaudhary J., Shannon J.G., Nguyen H.T. Genomic-assisted haplotype analysis and the development of high-throughput SNP markers for salinity tolerance in soybean. Sci Rep. 2016;6:19199. doi: 10.1038/srep19199.

Patil G., Mian R., Vuong T., Pantalone V., Song Q., Chen P., Shannon G.J., Carter T.C., Nguyen H.T. Molecular mapping and genomics of soybean seed protein: a review and perspective for the future. Theor Appl Genet. 2017;130(10):1975-1991.

Pham A.-T, Lee J.D., Shannon J.G., Bilyeu K.D. Mutant alleles of FAD2-1A and FAD2-1B combine to produce soybeans with the high oleic acid seed oil trait. BMC Plant Biol. 2010;10:195.

Ping J., Fitzgerald J. C., Zhang C., Lin F., Bai Y., Wang D., Aggarwal R., Rehman M., Crasta O., Ma J. Identification and molecular mapping of Rps11, a novel gene conferring resistance to Phytophthora sojae in soybean. Theor App/ Genet. 2015;129(2):445-51. doi: 10.1007/s00122015-2638-2.

Prince S.J., Song L., Qiu D., Maldonado Dos Santos J.V., Chai C., Joshi T. Patil G., Valliyodan B., Vuong T.D., Murphy M., Krampis K., Tucker D.M., Biyashev R., Dorrance A.E., Saghai Maroof M.A., Xu D., Shannon J.G., Nguyen H.T. Genetic variants in root architecture-related genes in a Glycine soja accession, a potential resource to improve cultivated soybean. BMC Genom. 2015;16:132. doi: 10.1186/s12864-0151334-6.

Qi B., Korir P., Zhao T., Yu D., Chen S., Gai J. mapping quantitative trait loci associated with aluminum toxin tolerance in NJRIKY recombinant inbred line population of soybean (Glycine max). J Integr Plant Biol. 2008;50:1089-1095. doi: 10.1111/j.1744-7909.2008.00682.x.

Qi Z., Pan J., Han X., Qi H., Xin D., Li W., Mao X., Wang Z., Jiang H., Liu C., Hu Z., Hu G., Zhu R., Chen Q. Identification of major QTLs and epistatic interactions for seed protein concentration in soybean unde multiple environments based on a high-density map. Mol Breed. 2016;36:55.

Reinprecht Y., Luk-Labey S.Y., Yu K., Rajcan I., Ablett G.R., Peter Pauls K. Molecular basis of seed lipoxygenase null traits in soybean line OX948. Theor Appl Genet. 2011;122(7):1247-1264 doi: 10.1007/ s00122-011-1528-5.

Rincker K., Diers B.W., Hartman G.L. Fine mapping of resistance genes from five brown stem rot resistance sources in soybean. Plant Gen. 2016;9(1). doi: 10.3835/plantgenome2015.08.0063.

Saghai Maroof M.A., Jeong S.C., Gunduz I., Tucker D.M., Buss G.R., Tolin S.A. Pyramiding of soybean mosaic virus resistance genes by marker-assisted selection. Crop Sci. 2008;48(2):517-526. doi.org/10.2135/ cropsci2007.08.0479.

Sahoo D.K., Abeysekara N.S., Cianzio S.R., Robertson A.E., Bhattacharyya M.K. A novel phytophthora sojae resistance Rps12 gene mapped to a genomic region that contains several Rps genes. PLoS ONE. 2017;12(1):e0169950. doi: 10.1371/journal.pone.0169950.

Santos M.A., Geraldi I.O., Garcia A.A.F., Bortolatto N., Schiavon A., Hungria M. Mapping of QTLs associated with biological nitrogen fixation traits in soybean. Hereditas. 2013;150:17-25.
Schlueter J.A., Lin J-Y., Schlueter S.D., Vasylenko-Sanders I.F., Deshpande S., Yi J., O'Bleness M., Roe B.A., Nelson R.T., Scheffler B.E., Jackson S.A., Shoemaker R.C. Gene duplication and paleopolyploidy in soybean and the implications for whole genome sequencing. BMC Genom. 2007;8:330.

Shi A., Chen P., Li D., Zheng C., Zhang B., Hou A. Pyramiding multiple genes for resistance to soybean mosaic virus in soybean using molecular markers. Mol Breed. 2009;23(1):113-124. https://doi.org/ 10.1007/s11032-008-9219-x.

Shoemaker R.C., Polzin K., Labate J., Specht J., Brummer E.C., Olson T., Young N., Concibido V., Wilcox J., Tamulonis J.P., Kochert G., Boerma H.R. Genome duplication in soybean (Glycine subgenus soja). Genetics. 1996;144:329-338.

Silva D.C.G., Yamanaka N., Brogin R.L., Arias C.A.A., Nepomuceno A.L. Di Mauro A.O., Pereira S.S., Nogueira L.M., Passianotto A.L.L., Abdelnoor R.V. Molecular mapping of two loci that confer resistance to Asian rust in soybean. Theor App/ Genet. 2008;117(1):57-63.

Singh R.K., Raipuria R.K., Bhatia V.S. et al. SSR markers associated with seed longevity in soybean. Seed Sci Technol. 2008;36:162-167.

Song Q.J., Marek L.F., Shoemaker R.C., Lark K.G., Concibido V.C., Dellanay X., Specht J.E., Cregan J.E. A new integrated genetic linkage map of the soybean. Theor Appl Genet. 2004;109:122-128.

SoyBase [Electronic resource]. Mode of access: http://soybeanbreeder stoolbox.org.

Sun L., Miao Z., Cai C., Zhang D., Zhao M., Wu Y., Zhang X., Swarm S.A., Zhou L., Zhang Z.J., Nelson R.L., Ma J. GmHs1-1, encoding a calcineurin-like protein, controls hard-seededness in soybean. Nat Genet. 2015;47:939-943. doi: 10.1038/ng.3339.

Suzuki M., Fujino K., Nakamoto Y., Ishimoto M., Funatsuki H. Fine mapping and development of DNA markers for the qPDH1 locus associated with pod dehiscence in soybean. Mol Breed. 2010;25:407418.

Swaminathan S., Das A., Assefa T., Knight J.M., Da Silva A.F., Carvalho J.P.S., Hartman G.L., Huang X., Leandro L.F., Cianzio S.R., Bhattacharyya M.K. Genome wide association study identifies novel single nucleotide polymorphic loci and candidate genes involved in soybean sudden death syndrome resistance. PLOS ONE. 2019. doi: 10.1371/journal.pone.0212071.

Tran D.T., Steketee C.J., Boehm J.D.Jr., Noe J., Li Z. Genome-wide association analysis pinpoints additional major genomic regions conferring resistance to soybean cyst nematode (Heterodera glycines Ichinohe). Front Plant Sci. 2019;10:401. doi: 10.3389/fpls.2019.00401.

Tripathi N., Khare D. Molecular approaches for genetic improvement of seed quality and characterization of genetic diversity in soybean: a critical review. Biotechnol Lett. 2016;38:1645-1654.

Tsubokura Y., Matsumura H., Xu M., Liu B., Nakashima H., Anai T., Kong F. Yuan X., Kanamori H., Katayose Y., Takahashi R., Harada K., Abe J. Genetic variation in soybean at the maturity locus E4 is involved in adaptation to long days at high latitudes. Agronomy. 2013;3:117-134. doi: 10.3390/agronomy3010117.

Valliyodan B., Ye H., Song L., Murphy M., Shannon J.G., Nguyen H.T. Genetic diversity and genomic strategies for improving drought and waterlogging tolerance in soybeans. J Exp Bot. 2017;68(8):1835-1849. doi: 10.1093/jxb/erw433.

Walker D.R., Scaboo A., Pantalone V., Wilcox J., Boerma H. Genetic mapping of loci associated with seed phytic acid content in CX1834-1-2 soybean. Crop Sci. 2006;46:390-397.

Wang F., Nan H., Chen, L., Fang C., Zhang H., Su T., Li S., Cheng Q., Dong L., Liu B., Kong F., Lu S. A new dominant locus, E11, controls early flowering time and maturity in soybean. Mol Breed. 2019;39:70. https://doi.org/10.1007/s11032-019-0978-3.

Wang J., Chu S., Zhang H., Zhu Y., Cheng H., Yu D. Development and application of a novel genome-wide SNP array reveals domestication history in soybean. Sci Rep. 2016;6:20728.

Wang Y., Han Y., Zhao X., Li Y., Teng W., Li D., Zhan Y., Li W. Mapping isoflavone QTL with main, epistatic and QTL $\times$ environment effects in recombinant inbred lines of soybean. PLoS ONE. 2015;10(3): e0118447. doi: 10.1371/journal.pone.0118447.

Wang Z., Zhou Z., Liu Y., Liu T., Li Q., Ji Y., Li C., Fang C., Wang M., Wu M., Shen Y., Tang T., Ma J., Tian Z. Functional evolution of phosphatidylethanolamine binding proteins in soybean and Arabidopsis. Plant Cell. 2015;27:323-336. 
Watanabe S., Hideshima R., Xia Z., Tsubokura Y., Sato S., Nakamoto Y., Yamanaka N., Takahashi R., Ishimoto M., Anai T., Tabata S., Harada K. Map-based cloning of the gene associated with the soybean maturity locus E3. Genetics. 2009;182(4):1251-62. doi: 10.1534/genetics. 108.098772 .

Watanabe S., Xia Z., Hideshima R., Tsubokura Y., Sato S., Harada K. A map-based cloning strategy employing a residual heterozygous line reveals that the GIGANTEA gene is involved in soybean maturity and flowering. Genetics. 2011;188:395-407. doi: 10.1534/genetics. 110.125062 .

Willmot D.B., Nickell C.D. Genetic analysis of brown stem rot resistance in soybean. Crop Sci. 1989;29:672-674. doi: 10.2135/cropsci1989.001 1183X002900030026x.

Wu M., Wu W.P., Liu C.C., Liu Y.-N., Wu X.-Y., Ma F.-F., Zhu A.-Q., Yang J.-Y., Wang B., Chen J.-Q. A bean common mosaic virus (BCMV)-resistance gene is fine-mapped to the same region as Rsv1-h in the soybean cultivar Suweon 97. Theor Appl Genet. 2018;131(9):1851-1860. doi: 10.1007/s00122-018-3117-3.

Xia Z., Watanabe S., Yamada T., Tsubokura Y., Nakashima H., Zhai H., Anai T., Sato S., Yamazaki T., Lü S., Wu H., Tabata S., Harada K. Positional cloning and characterization reveal the molecular basis for soybean maturity locus E1 that regulates photoperiodic flowering. Proc Natl Acad Sci USA. 2012;109:E2155-E2164.

Xie D., Han Y., Zeng Y., Chang W., Teng W., Li W. SSR- and SNP-related QTL underlying linolenic acid and other fatty acid contents in soybean seeds across multiple environments. Mol Breed. 2012;30:169-179.

Xu M., Yamagishi N., Zhao C., Takeshima R., Kasai M., Watanabe S. Kanazawa A., Yoshikawa N., Liu B., Yamada T., Abe J. The soybeanspecific maturity gene E1 family of floral repressors controls nightbreak responses through down-regulation of FLOWERING LOCUS T orthologs. Plant Physiol. 2015;168:1735-1746.

Xu X., Zeng L., Tao Y., Vuong T., Wan J., Boerma R., Noe J., Li Z., Finnerty S., Pathan S.M., Shannon J.G., Nguyen H.T. Pinpointing genes underly ing the quantitative trait loci for root-knot nematode resistance in palaeopolyploid soybean by whole genome resequencing. Proc Nat Acad Sci USA. 2013;1 10:13469-13474. doi: 10.1073/pnas.1222368110.

Xun H., Yang X., He H., Wang M., Guo P., Wang Y., Pang J., Dong Y., Feng X., Wang S., Liu B. Over-expression of GmKR3, a TIR-NBS-LRR type R gene, confers resistance to multiple viruses in soybean. Plant $\mathrm{Mo}$ Biol. 2019;99(1-2):95-111.

Yan L., Hofmann N., Li S., Ferreira M.E., Song B., Jiang G., Ren S., Quigley C., Fickus E., Cregan P. Song Q. Identification of QTL with large effect on seed weight in a selective population of soybean with genome-wide association and fixation index analyses. BMC Genom. 2017;18:529.

Yang K., Moon J.K., Jeong N., Chun H.K., Kang S.T., Bac K. Jeong S.-C. Novel major quantitative trait loci regulating the content of isoflavone in soybean seeds. Genes \& Genomics. 2011;33:685-692. doi: 10.1007/ s13258-011-0043-z.
Yang Q., Yang Y., Xu R., Lv H., Liao H. Genetic analysis and mapping of QTLs for soybean biological nitrogen fixation traits under varied field conditions. Front Plant Sci. 2019;10:75. doi: 10.3389/fpls.2019. 00075.

Yang X., Niu L., Zhang W., He H., Yang J., Xing G., Guo D., Zhao Q. Zhong X., Li H., Li Q., Dong Y. Increased multiple virus resistance in transgenic soybean overexpressing the double-strand RNA-specific ribonuclease gene PAC1. Transgenic Res. 2019;28(1):129-140.

Yue Y., Liu N., Jiang B., Li M., Wang H., Jiang Z., Pan H., Xia Q., Ma Q., Han T., Nian H. A single nucleotide deletion in J encoding GmELF3 confers long juvenility and is associated with adaption of tropic soybean. Mol Plant. 2017;10:656-658.

Zhai H., Lü S., Wu H., Zhang Y., Zhang X., Yang J., Wang Y., Yang G., Qiu H., Cui T., Xia Z. Diurnal expression pattern, allelic variation, and association analysis reveal functional features of the E1gene in control of photoperiodic flowering in soybean. PLOS ONE. 2015;10(8): e0135909.

Zhang B., Chen P., Chen C. Y., Wang D., Shi A., Hou A., Ishibashi T. Quantitative trait loci mapping of seed hardness in soybean. Crop Sci. 2008; 48(4):1341-1349.

Zhang C., Gao H., Li R., Han D., Wang L., Wu J., Xu P., Zhang S. GmBTB/ $\mathrm{POZ}$, a novel BTB/POZ domain-containing nuclear protein, positively regulates the response of soybean to Phytophthora sojae infection. Mol Plant Pathol. 2019;20(1):78-91. doi: 10.1111/mpp.12741.

Zhang J., Song Q., Cregan P. B., Jiang G-L. Genome-wide association study, genomic prediction and marker-assisted selection for seed weight in soybean (Glycine max). Theor Appl Genet. 2016;129(1):117130.

Zhang S.R., Wang H., Wang Z., Ren Y., Niu L., Liu, J., Liu B. Photoperiodism dynamics during the domestication and improvement of soybean. Sci China Life Sci. 2017;60:1416-1427.

Zhao C., Takeshima R., Zhu J., Xu M., Sato M., Watanabe S., Kanazawa A., Liu B., Kong F., Yamad, T., Abe J. A recessive allele for delayed flowering at the soybean maturity locus E9 is a leaky allele of FT2a, a FLOWERING LOCUS T ortholog. BMC Plant Biol. 2016;16:20.

Zhong C., Li Y., Sun S., Duan C., Zhu Z. Genetic mapping and molecular characterization of a broad-spectrum phytophthora sojae resistance gene in chinese soybean. Int J Mol Sci. 2019;20(8):1809.

Zhou L., Wang S.B., Jian J., Geng Q. C., Wen J., Song Q., Wu Z., Li G-J., Liu Y-Q., Dunwell J.M., Zhang J., Feng J-Y., Niu Y., Zhang L., Ren W-L., Zhang Y-M. Identification of domestication-related loci associated with flowering time and seed size in soybean with the RAD-seq genotyping method. Sci Rep. 2015;5:9350.

Zhou Z., Jiang Y., Wang Z., Gou Z., Lyu J., Li W., Yu Y., Shu L., Zhao Y., Ma Y., Fang C., Shen Y., Liu T., Li C., Li Q., Wu M., Wang M., Wu Y., Dong Y., Wan W., Wang X., Ding Z., Gao Y., Xiang H., Zhu B., Lee S.H., Wang W., Tian Z. Resequencing 302 wild and cultivated accessions identifies genes related to domestication and improvement in soybean. Nat Biotechnol. 2015;33:408-414.

Конфликт интересов. Авторы заявляют об отсутствии конфликта интересов.

Поступила в редакцию 15.07.2020. После рецензирования 14.08.2020. Принята к публикации 17.08.2020. 